\title{
IMPACT OF EXERCISE ON BRAIN RESPONSES TO VISUAL FOOD CUES:
}

\section{AN FMRI STUDY}

\section{A Thesis}

presented to

the Faculty of Polytechnic State University,

San Luis Obispo

\author{
In Partial Fulfillment \\ of the Requirements for the Degree \\ Master of Science in Kinesiology
}

by

Nero Erezi Evero

June 2011 
(C) 2011

Nero Erezi Evero

ALL RIGHTS RESERVED 


\section{COMMITTEE MEMBERSHIP}

TITLE:

Impact of Exercise on Brain Responses to Visual Food Cues: An fMRI Study

AUTHOR: $\quad$ Nero Erezi Evero

DATE SUBMITTED: June 2011

COMMITTEE CHAIR: $\quad$ Todd Hagobian, $\mathrm{PhD}$

COMMITTEE MEMBER: Robert Clark, PhD

COMMITTEE MEMBER: Suzanne Phelan, PhD 


\begin{abstract}
Impact of Exercise on Brain Responses to Visual Food Cues: An fMRI Study Nero Erezi Evero
\end{abstract}

On the basis of a strong body of data, the Institute of Medicine currently recommends at least 60 minutes of exercise per day to prevent body weight gain overtime. Previous studies have shown that there is no compensatory increase in food intake with this dose of exercise. Ultimately, the brain decides whether to alter food intake. Surprisingly, no published studies have assessed the impact of exercise on brain activation. Using functional magnetic resonance imaging (fMRI) and an appetite questionnaire, we investigated the effects of a single bout of aerobic exercise on brain responses to visual food cues and subjective appetite responses. After an overnight fast, $30(17 \mathrm{M}, 13 \mathrm{~W})$, healthy, habitually active subjects $\left(22.0 \pm 3.8\right.$ years, $23.6 \pm 2.4 \mathrm{~kg} / \mathrm{m}^{2}$, $44.3 \pm 8.3 \mathrm{~mL} \cdot \mathrm{kg}^{-1} \cdot \mathrm{min}^{-1}$ ) either rested or exercised for 60 minutes, in a counterbalanced crossover design. Immediately after each condition, blood oxygen dependent levels were determined in response to visual food cues of different energy value during an fMRI scan. Exercise showed significantly greater activation $(\mathrm{P}<.005$, uncorrected $)$ in regions implicated in food inhibition (superior frontal gyrus, medial surface), and visual attention (precuneus, superior temporal gyrus, middle temporal gyrus and fusiform gyrus) regions. However, exercise did show a greater activation in a food reward region (medial orbitofrontal cortex). The rest condition only showed greater activation in a visual center (fusiform gyrus) and the midbrain. In addition, relative to no-exercise, subjective appetite responses were suppressed following the exercise bout. Taken altogether, these 
data suggest exercise may impact the brain in a direction expected to suppress food intake and increase food attention, which is in line with previous behavioral, biological and fMRI data. These findings may explain, at least partially, why aerobic exercise does not lead to a compensatory increase in food intake. 


\section{ACKNOWLEDGEMENTS}

I owe my deepest gratitude to my thesis advisor and mentor Dr. Todd Hagobian. Dr. Hagobian was deeply committed and unwavering to assist me throughout the entire research process and then some. I am very grateful for the time and energy Dr. Hagobian invested in my development as a scientist and professional. Without his knowledge, expertise and support, this thesis would have not been possible.

I would also like to thank my thesis committee members, Dr. Robert Clark and Dr. Susan Phelan. Their knowledge, enthusiasm, encouragement and suggestions really enhanced the quality of my thesis.

I would also like to thank the undergraduate assistants, Laura Hackett, Simone Mata and Casey Osmond for their tremendous effort and outstanding work with the data collection. In addition I would like to thank our MRI technician, Mike DiDonna.

I would like to further extend my appreciation to my parents, Dennis and Mary, both my brothers Ighe and Ejiro and my sisters Reva and Mano for their continued love and support.

Finally, a special thank you to my fellow graduate students who have been a great encouragement and support throughout the entire graduate endeavor. 


\section{TABLE OF CONTENTS}

Page

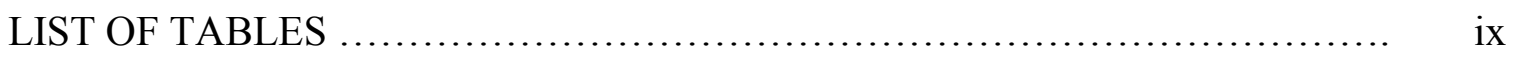

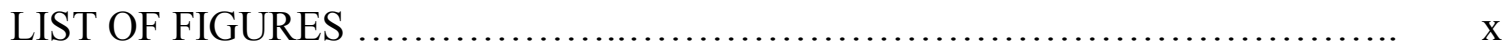

\section{CHAPTER}

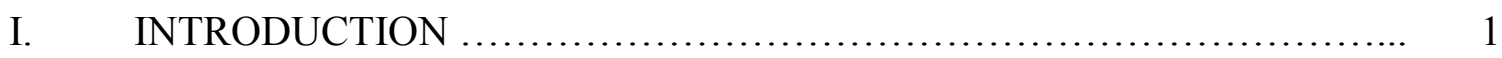

Statement of Problem ...................................... 1

Impact of Short-term Exercise on Energy Balance ............... 1

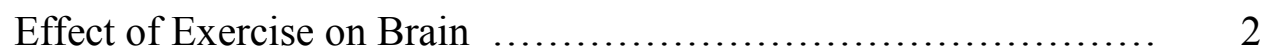

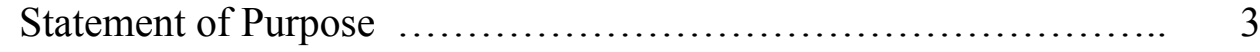

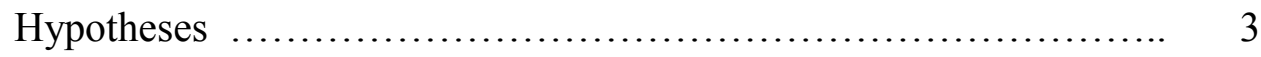

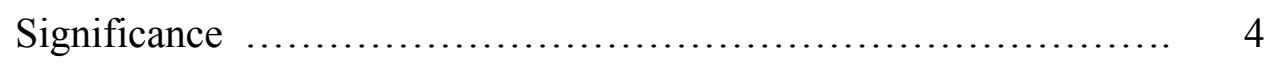

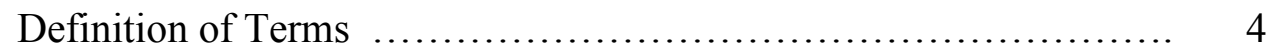

II. LITERATURE REVIEW ........................................ 6

Effect of Exercise on Energy Balance $\ldots \ldots \ldots \ldots \ldots \ldots \ldots \ldots \ldots \ldots . \ldots$

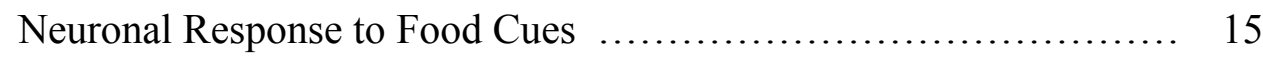

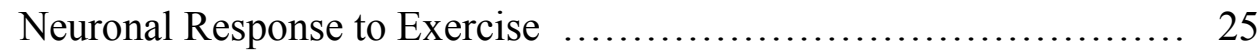

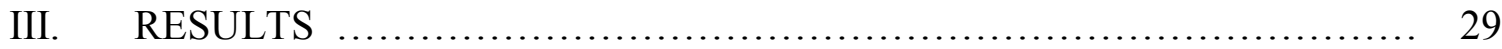

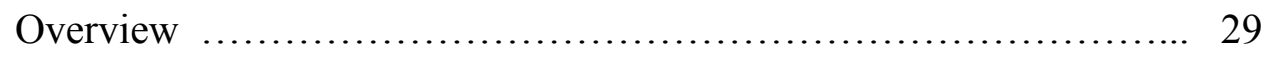

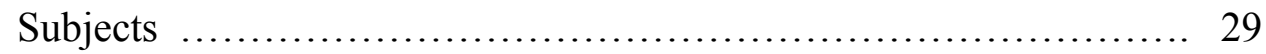

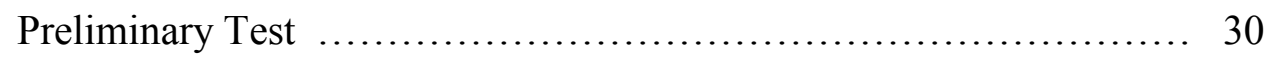

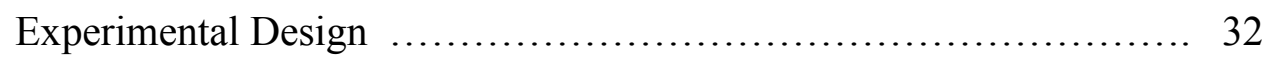




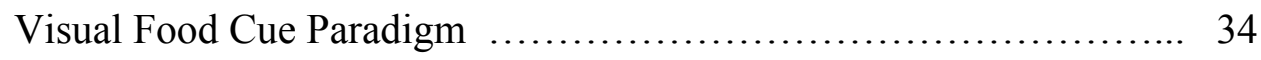

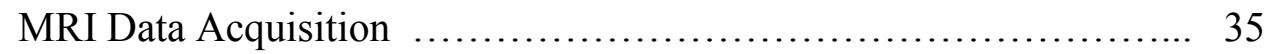

fMRI Data Processing and Statistical Analysis $\ldots \ldots \ldots \ldots \ldots \ldots \ldots . \ldots . \ldots 5$

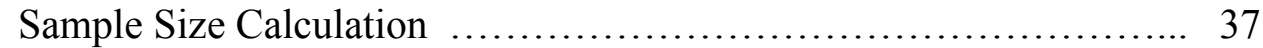

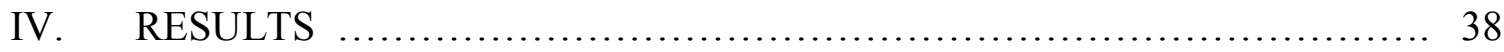

Assessment of Recruitment and Compliance $\ldots \ldots \ldots \ldots \ldots \ldots \ldots \ldots . \ldots 38$

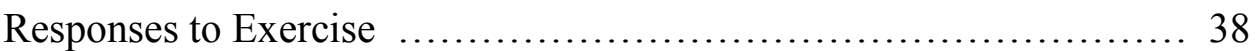

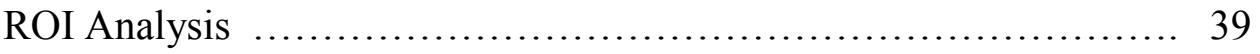

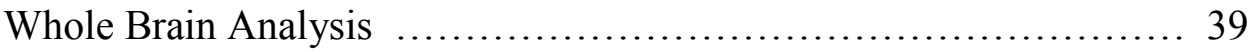

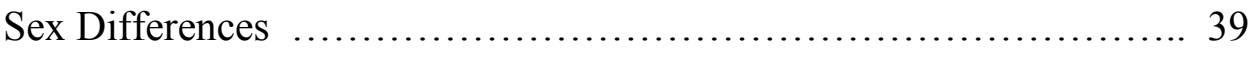

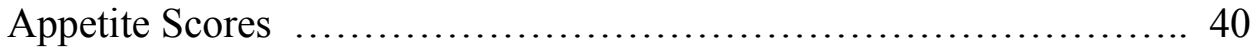

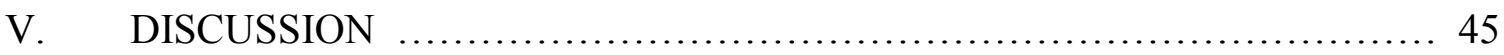

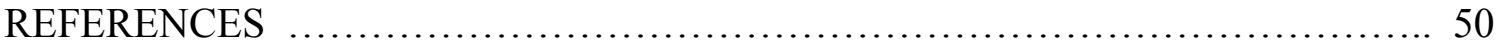

\section{APPENDICES}

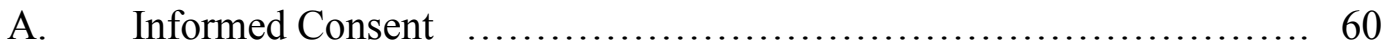
B. Health \& Fitness History Questionnaire $\ldots \ldots \ldots \ldots \ldots \ldots \ldots \ldots \ldots . \ldots 5$

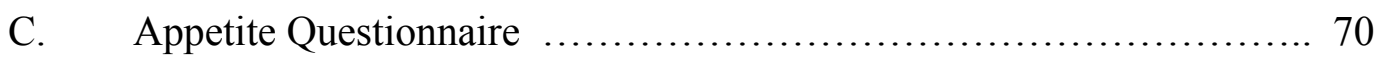




\section{LIST OF TABLES}

Page

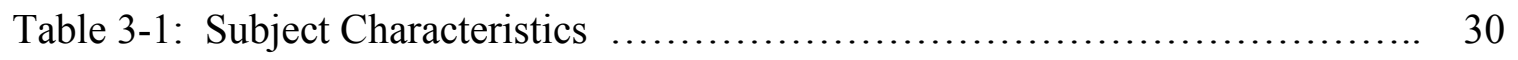

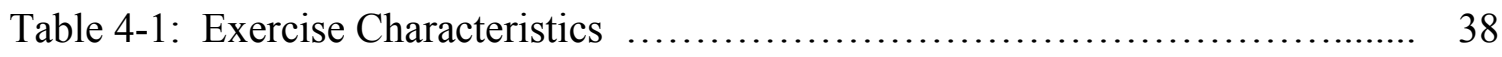

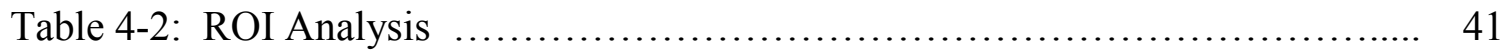

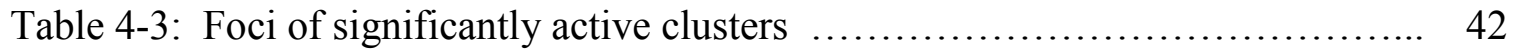




\section{LIST OF FIGURES}

Page

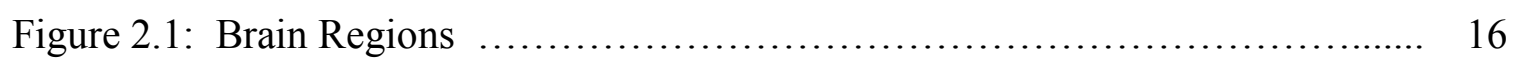

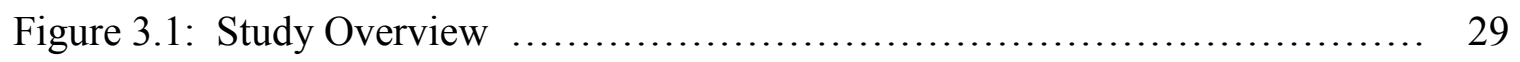

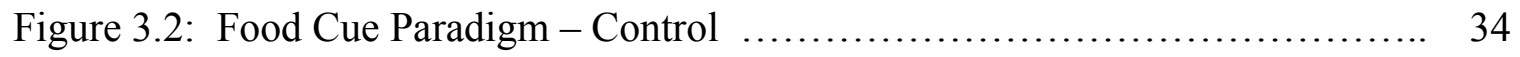

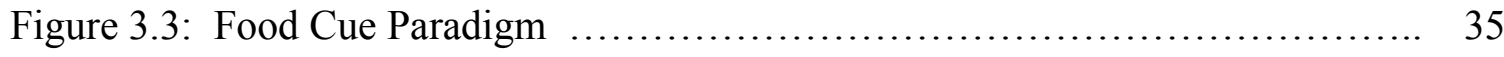

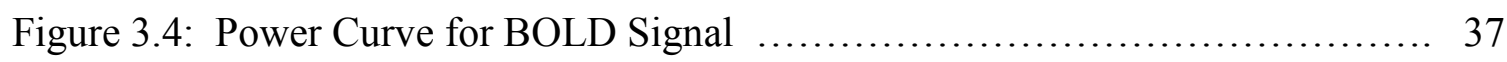

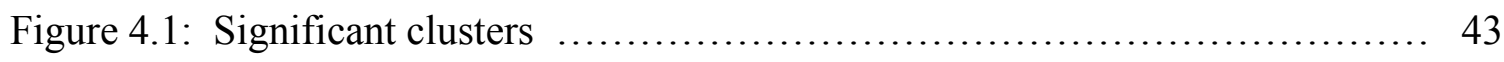

Figure 4.2: Brain Activation of exercise vs. no-exercise $\ldots \ldots \ldots \ldots \ldots \ldots \ldots \ldots \ldots \ldots .43$

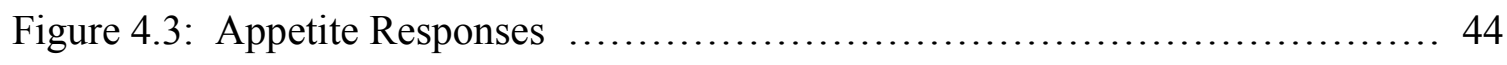




\section{Chapter 1}

\section{Introduction}

\section{Statement of Problem}

Obesity has reached epidemic proportions despite being a preventable disease (27). Such increases will tremendously affect public health since obesity is strongly associated with an increased risk of chronic diseases such as cardiovascular disease and Type-2 diabetes (87). To further exacerbate the issue, the prevalence of overweight and obese adults has steadily grown so that projection models have predicted $\sim 90 \%$ of all Americans will be overweight or obese by 2030 (123). Regular exercise is considered a 'cornerstone' of obesity management because it affects both sides of the energy balance equation; that is energy expenditure and energy intake. For example, exercise increases energy expenditure and decreases body weight in men and women (124). Recently, considerable attention has focused on the effect of exercise on altering subjective appetite (11) and energy intake (59).

\section{Impact of Short-term Exercise on Energy Balance}

In a series of studies, Broom et al. $(11,12)$ showed that a single-bout of exercise $\left(60 \mathrm{~min},>70 \% \mathrm{VO}_{2 \max }\right)$ decreased subjective appetite (e.g. hunger and desire to eat specific foods), as measured by a visual analog scale. In line with the results, others have found that short-term exercise decreases actual energy intake. For example, Stubbs et al. (108) found that men do not show any compensatory adjustments of energy intake after exercise ( $4000 \mathrm{kcal} / \mathrm{day})$ in comparison to women (109) who showed partial 
compensation of energy intake as a result of the high levels of exercise over seven days. Unick et al. (119) reported overweight and obese women did create a short-term $(\sim 2 \mathrm{hrs})$ energy deficit following a single bout of exercise (70-75\% age predicted $\left.\mathrm{HR}_{\max }\right)$. Taken together, these data suggest that a single bout of exercise can assist in weight control efforts by not increasing energy intake despite increasing energy expenditure.

\section{Effect of Exercise on Brain}

Energy intake is ultimately determined by the brain through a complex interaction of internal (e.g. energy stores and circulating appetite hormones) and external (e.g. visual food cues, taste and smells) signals. Surprisingly, there is little data on the impact of exercise on brain activation $(3-5,46,75,127,128)$. The exercise studies that did incorporate neuroimaging (using functional magnetic resonance (fMRI), functional magnetic spectroscopy (fMRS), positron emission tomography (PET), and near infrared spectroscopy (NIRS), were mainly concerned with characterizing brain activation during static and dynamic fatigue tasks $(3-5,75)$ or investigating the effects of exercise on cardiovascular regulation $(127,128)$. Therefore, selective evidence suggests exercise may induce 'transient hypofrontality', which is a temporary inhibition of certain brain regions that are not directly essential to performing and maintaining the exercise, or physiological homeostasis $(4,23,24,129)$. For example, Janse Van Rensburg et al. (46) demonstrated following a single bout of exercise and visual smoking cues, smokers showed no activation (compared to the control group) in the orbitofrontal cortex (which is involved in enhancing the salience of a stimuli), while other areas of the prefrontal cortex associated with normal resting state (specifically Broadman Area 10) showed 
increased activation. Their data suggest that exercise may selectively impair blood flow to higher cognitive prefrontal regions post-exercise and thus reducing the salience of the stimuli. However, to date there are no published studies on the effect of brain activation to visual food cues post-exercise.

\section{Statement of Purpose}

The purpose of the study is to determine whether a single bout of exercise alters food reward, visual attention, and inhibitory control regions in the brain assessed by fMRI and subjective appetite responses.

\section{Hypotheses}

Primary Hypotheses: Relative to a no-exercise condition, a single bout of exercise will:

1. Yield significantly greater activation in regions associated with inhibitory control (e.g. dorsolateral prefrontal cortex).

2. Have an inhibitory effect on reward regions (e.g. orbitofrontal cortex) of the brain.

3. Yield significantly greater activation in regions associated with visual attention (e.g. fusiform gyrus) of the brain.

4. Attenuate BOLD signal activation in regions associated with regulation of energy intake (e.g. hypothalamus and insular cortex).

5. Will have a significant suppression of subjective feelings of appetite (e.g. hunger and desire for certain types of food immediately). 


\section{Significance}

Several decades of poor body weight management by Americans has propelled obesity to the top of the list of major health concerns. Exercise is an effective method for body weight management via increases in energy expenditure and transient decreases in food intake; more so in men than women (109). Unfortunately, it is still unclear how to best control food intake and prevent increases in body weight. Understanding the influence exercise has on areas in the brain controlling appetite, ingestion, and food reward will elucidate the complexity of neurobiology of food-related processing and help provide the best method of managing body weight. Ultimately, the additional insight of the role exercise plays in processing the motivational salience of food stimuli will help design comprehensive interventions that better aids in the prevention of weight gain and obesity.

\section{Definition of Terms}

The following terms and abbreviations are defined as used in the study:

Blood Oxygen Level Dependent (BOLD): the source of contrast in fMRI; correlated with neuronal activity (30).

Connectivity: the systematic approach to determine the influence one neural system has on another (30).

Functional Magnetic Resonance Imaging (fMRI): a type of specialized magnetic resonance scan that measures the hemodynamic response (change in blood flow) related to neural activity in the brain or spinal cord of humans or other animals (30). 
Region of Interest (ROI): a selected subset of areas within the brain that is associated with regulation of appetite and energy intake (30).

Statistical Parametric Mapping software (SPM): is a voxel-based approach, employing classical inference, to make some comment about regionally specific responses to experimental factors (30). 


\section{Chapter 2}

\section{Literature Review}

In the face of the current obesity epidemic (27) and widespread levels of physical inactivity (79), it is extremely important to understand how exercise impacts different aspects of appetite and food intake in humans. The regulation of appetite and food intake is more than the physiological processes involved in energy homeostasis, but the neurological response to perturbations in energy balance (EB) from both internal (e.g. nutritional state) and external (i.e. visual, smell, and taste inputs) sensory input. Although exercise has been shown to be shown to have a modest impact on weight management (13), the interaction between the physiological and neurological factors that affect the brain response to food is complex; thus making it difficult to determine the impact of exercise on these factors. Therefore, it is important to understand how exercise impacts appetite and eating behavior in order to achieve a better knowledge of the etiology and/or treatments for preventing weight gain and obesity. Hence, the purpose of this review is twofold; to determine the effect of exercise on appetite and energy intake (EI) and elucidate the brain's response to food stimuli.

\section{Effect of Exercise on Energy Balance}

Exercise and its effect on energy homeostasis has been widely studied over the last 60 years, but it is still unclear how it impacts the regulation of EB. There are examples in the literature that suggest exercise intensifies hunger and increases food intake (79), thus diminishing its effect as a viable method for weight control. However, 
the literature does not fully support this claim in either animal or human subjects $(1,2$, $11,12,14,43,45,52-57,59,73,77,78,80,81,103,114,119)$. To better understand the relationship between exercise on appetite and EI, current findings on the topic will be summarized in the following sections. Due to potentially different mechanisms operating the complex system that regulates appetite and EB (9), this review will focus primarily on the effects of short-term exercise on EB.

\section{Effect of short-term exercise on appetite response}

Subjective appetite responses are actually affected by changes in energy balance.

For example, energy deficit induced by decreasing EI, increases perception of hunger and desire to eat (43). On the other hand, an energy deficit created by increasing EE via exercise, suppresses appetite responses in a direction expected to decrease EI. The majority of studies have shown that an acute bout of exercise does not increase postexercise subjective feelings of hunger $(2,11,12,14,43,45,52-57,59,77,78,81,85$, $103,114,116,117,125)$. Furthermore, vigorous exercise ( $>70 \% \mathrm{VO} 2 \mathrm{max})$ for long durations (>50 min) transiently suppresses hunger during and immediately (anywhere from 5 min to $2 \mathrm{hrs})$ after exercise $(11,12,14,55,56,85,114,116,125)$. In a wellcontrolled study designed to assess the differences between high (70\% VO2max) and low (30\% VO2max) intensity exercise (given total EE was held constant), King et al. (56) showed that high intensity exercise lead to the suppression of hunger 15 minutes after the termination of exercise. This phenomenon has been termed 'exercised-induced anorexia' and was corroborated by King and colleagues (55). More recently, similar findings have 
been observed in a series of studies $(11,12)$ that included well-trained lean male subjects engaged in high intensity aerobic exercise.

Interestingly, 'exercise-induced anorexia' has been reported in obese males (125), increasing the appeal of aerobic exercise as an effective weight control method. Although 'exercise-induced anorexia' has been traditionally associated with high intensity exercise $(>70 \% \mathrm{VO} 2 \mathrm{max})$, few studies have reported the incident after moderate intensity exercise (14). However, to date, only one study has reported a significant suppression of hunger, post-exercise, in women (85). In fact, the literature suggests woman have no significant changes in post-exercise (compared to pre-exercise) subjective measures of hunger, regardless of exercise intensity and duration $(43,57,59$, 77, 81, 119). This implies that exercise (of the same intensity and duration) does not suppress subjective hunger to the same extent in females as males, while also alluding to different mechanisms involved in appetite control between men and women.

Despite exercise inducing a transient suppression of appetite, investigators have shown actual food intake following an acute bout of exercise was not significantly different when compared to a control (no-exercise condition) group $(52,58)$. This suggests that 'exercise-induced anorexia', more specifically the suppression of hunger post-exercise, may have no real significance on subsequent EI, at least in women. In addition, since the duration of this 'exercise-induced anorexia' has been reported to brief $(<2$ hours) $(56,114)$ it may have no marked effect on EI $(52,58)$. Furthermore, the difference in 'exercise-induced anorexia' between males and females may not be of any importance regarding ensuing EI as well. Further work is needed to examine the potential interactive effects between 'exercise-induced anorexia' and subsequent EI. 
In summary, the available literature suggests:

- An acute bout of moderate or high intensity exercise does not alter subjective appetite responses in a direction expected to stimulate energy intake in lean or obese men and women.

- High intensity exercise temporarily suppresses subjective perceptions of hunger post-exercise.

- Men, compared to women, have lower hunger and desire to eat rating after exercise.

\section{Effect of short-term exercise on energy intake}

The relationship between exercise-induced energy deficits and EI was once subject to scrutiny. The classic work frequently referred to is that of Edholm et al. (25); where they reported, after accurate measurement of EE and EI, a positive relationship with EE one day and EI two days later. Edholm et al. (25) eventually concluded there was a two day lag in energy compensation after producing an energy deficit. In fact, similar findings were reported by Mayer et al. (82), who showed that rats exercising on a treadmill $(<1 \mathrm{hr} /$ day) did not increase their EI, but showed a significant decrease in EI. However, after subsequent attempts in human subjects by Edholm (26), the results were unable to be replicated. Therefore at the time, the popular belief was exercise induces an automatic physiological drive in hunger and food intake. This intuition possibly persisted as a result of Lawton et al. (69) findings', which alluded to the body's sensitive compensatory mechanism to oppose energy deficit induced by food restriction or 
substantial energy differentials between two meals. Nevertheless, Hubert et al. (43) evaluated the method of inducing energy deficit via food restriction to an exerciseinduced energy deficit in the same subjects. The results confirmed that food deprivation significantly increased hunger and EI, whereas the exercise-induced energy deficit did not. This suggests the physiological responses to food deprivation are quite different from the physiological responses induced by an acute bout of exercise.

Mixed results have been reported on the effect of short-term exercise on actual EI. Some of these discrepancies to show a beneficial effect of acute exercise on EB may reflect substantial differences in experimental protocol (e.g. type of exercise, intensity, duration, interval between exercise and test meal, nutritional state prior to exercise, macronutrient composition of test meal, accurate and precise measurement of food intake and exercise-induced EE and environmental and social factors) as well as basic biological (e.g. species, sex, weight classification, and eating behavior) characteristics of the subjects. For example, some studies found that an acute bout of exercise between 70 and $80 \% \mathrm{HR}_{\max }$ led to a compensatory increase in $\mathrm{EI}$ in the short-term $(68,120)$, whereas others found a decrease in absolute EI subsequent to an acute bout of exercise at moderate intensities $(59,116,117,125)$. However, the majority of studies $(2,45,52,54-$ $56,77,78,80,81,85,114,119)$ found no significant difference in either subsequent EI or 24-hr EI. The most consistent methodological limitation within the literature derived from the fact that some investigators did not account for the energy cost associated with exercise (i.e. the energy deficit induced by exercise-induced EE).

To overcome this limitation and assure results were not interpreted in a way that suggests that exercise is not a modulator of EI; the concept of relative EI (EI - net energy 
cost of exercise) was created by King et al. (56). Therefore, after further examination, the majority of evidence $(2,14,45,52-56,59,77,78,80,81,85,92,114,116,117,119$, 125) suggests that a short-term energy deficit (produced by exercise) can be achieved even in the presence of a compensatory increase in absolute EI; given EE during exercise is greater than the increase in EI. However, energy deficits created by exercise can be abolished if a high-fat (energy dense) food is selected after completing an exercise session. For example, after an acute bout of both high- and moderate-intensity exercise, relative energy intake was considerably increased when subjects were exposed to a highfat lunch, compared to a low-fat lunch, despite the total weight of food consumed being lower $(55,77)$. This finding seems to be well documented and has been termed the 'fat paradox' (8). Interestingly, meal palatability for both meals (high-fat and low-fat) were equivocal, thus the effect cannot be attributed to the high-fat lunch being more palatable than low-fat lunch.

In general, men do not increase energy intake in response to exercise (108), whereas women at least partially compensate by increasing energy intake to meet the new higher energy expenditure (109). In an indirect comparison of three similar studies (i.e. exercise at intensity of $\sim 70 \mathrm{VO} 2 \mathrm{max}$ and exercise-induced EE of $\sim 350 \mathrm{kcal}$ ), normalweight men $(56,114)$ showed no compensatory increase in absolute EI. On the other hand normal-weight women (92) increased their EI about $125 \mathrm{kcal}$ when compared to the control group. These findings seem to be consistent amongst both dietary restrained (77) and unrestrained (57) women. Nevertheless, after taking into account the net cost of exercise, both men $(56,114)$ and women $(92)$ had created an energy deficit. These findings suggest there may be an interaction with an acute bout of high-intensity exercise 
and sex in determining post-exercise EI in the short-term. Further studies will need direct comparison of the two sexes to reveal any true relationship, if one exists.

Similar differences have been noted when comparing obese to non-obese.

Klissileff et al. (59) and Unick et al. (119) reported obese women had no significant change in absolute EI following an acute bout of moderate-intensity exercise when compared to other obese women. However, there was a significant decrease in relative EI, when the energy cost of exercise was taken into account. In contrast, compared to the resting condition, Ueda et al. (117) and Weterterp-Plantenga et al. (125) showed that obese men have a significant decrease in both absolute and relative EI after an acute bout of moderate-intensity exercise. These findings suggest obese women may be inclined to maintain their body weight as opposed to their obese male counterparts.

In summary, the available literature suggests:

- Increased EE due to exercise of moderate- to high-intensity does not increase EI in men. But women have a partial compensation to increase energy intake in response to exercise.

- Selecting high-fat (energy dense) foods after exercise can jeopardize the energy deficit created by exercise.

- In obese men and women, large energy deficits induced by exercise do not lead to acute compensatory responses to EI. 


\section{Potential short-term homeostatic mechanisms}

Even though the reason for absences in compensatory effects in response to an acute bout of exercise is not clearly understood, it is of note to mention the potential mechanisms. Clearly certain factors associated with exercise have some limit to the extent which subjects compensate EI in the short-term (1-3 days). In a review by Blundell et al. (9), it was suggested the priority to defend fluid balance (in the short-term) exceed the body's need to restore EB in response to the exercise-induced energy deficit in the short-term. This suggests water balance is more tightly guarded than EB $(106,107)$, thus it may play a part in the slow response of EI.

Woods (132) suggests for homeostatic reasons, increased endogenous energy should have an inhibitory effect on food intake. In Woods' 'eating paradox theory', he states although necessary for energy replenishment, eating can be disruptive to energy homeostasis, due to the increased levels of digested glucose and fatty acids absorbed into the blood. On a chronic basis, elevated glucose and fatty acids in the blood are associated with metabolic abnormalities including, obesity, metabolic syndrome, type 2 diabetes, and cardiovascular disorders. Hence, the body will temporarily inhibit food intake (132). Researchers have shown exercise is associated with the mobilization of endogenous fuels $(99,100)$, therefore feeding should be simultaneously inhibited to prevent higher levels in the blood. According to Woods (132), the suppression of food intake post-exercise creates "a metabolically 'safe' interval when the impact of the meal is likely to be minimal". However, the predominant hypothesis that has recently been gaining consideration seems that exercise suppresses orexigenic (e.g. acylated ghrelin) $(11,11$, 54) hormones and increases anorexigenic hormones (e.g. GLP-1, insulin and PYY $3-36$ ) 
$(54,117)$. Collectively, these appetite-regulating hormones act in a manner to suppress energy intake.

\section{Impact of exercise on weight control}

The usefulness of exercise as a means to control body weight has been questioned by some investigators (34). However, this could be a consequence of failure to comply with the prescribed exercise regimen. The effects of regular exercise on weight management $(130,131)$ are beneficial if the exercise program is adhered to. In fact, Stubbs et al. (110) demonstrated a 7 day sedentary routine does not induce a compensatory decrease in EI, subsequently leading to an energy surplus. These findings only reinforce the importance of regular exercise. Actually, in the short-term compared to dieting, exercise may be more effective in producing an energy deficit, since exercise fails to induce any significant changes in neither hunger nor EI (43). Furthermore, longer interventions ( $\leq 7$ days) have shown exercise is able to produce an energy deficit, with no compensatory increase in men and partial compensation (108), about 30\%, in women (109).

The weak coupling between EE and EI (in the short- and long-term) can have positive implications for weight management in obese populations as well. In a longterm (i.e. 8 weeks) study, Woo et al. (130) reported exercise-induced EE led to no significant changes in average EI and subsequent body mass loss ranging from 5.7 - 6.84 $\mathrm{kg}$ (with the majority coming from fat). These findings suggest that in a state of energy surplus, there is a possible uncoupling of EI from EE over longer periods. Ultimately, regardless of exercise regimen, sex or weight status, the system must return to 
equilibrium. However, the combination of exercise and energy restriction (via a low-fat diet could) could be used advantageously to control appetite, prevent overconsumption and protect against the development or progression of obesity.

\section{Neuronal Response to Food Cues}

Eating is a complex behavior that is not simply turned on and off by signals of energy state. In a review by Kringlebach and Stein (64), it was reported that human's nutritional homeostasis is not the only motivation to consume food. Other motivations to feed can be traced to rewarding features of highly palatable food, temporal factors (e.g. time of day), emotion and cognition (e.g. learning, memory, environmental and social cues) (7). Ultimately, the decision to initiate food intake, how much to consume and when a meal is terminated is influenced by the interaction between homeostatic regulation of EI and "non-homeostatic" EI (62), also known as hedonic eating - a type of eating that can override the satiety signals of energy surplus, in certain subjects (62). Taken as a whole, the decision to eat is finally determined after the brain has processed both the internal and external stimuli.

The ability to study neural networks that influence eating behavior in humans has improved considerably with significant advances in neuroimaging technology, for example positron emission tomography (PET) scans and fMRI. The detection of regional cerebral blood flow (rCBF) and BOLD signals (both indicators of neural activity) have helped identify the neural systems regulating human feeding. In recent years, the technology has been applied to study appetite by using food cues to elicit a neuronal response that is associated with specific patterns of $\mathrm{rCBF}$ or BOLD signals. Food-related 
visual cues such as taste, smell, texture, and appearance all influence motivation to eat (95). However, environmental visual cues are one of the initial and key inputs that signal the potential availability of food, which affect the motivation to initiate a meal (72). Hence, the following discussion will summarize the current literature of neuronal responses of both visual food stimuli and eating in obese-resistant (e.g. normal-weight persons) - individuals who "adapt" effectively to periods of energy surplus (7), and the obese-prone (e.g. overweight, reduced obese, obese persons) - individuals who do not “adapt" effectively to periods of energy surplus (7), in various energy states (e.g. fasted, eucaloric state and overfeed state). However, to date no other study has examined the brain's response to exercise, since in essence, exercise, is another way to induce a change in energy states by creating an energy deficit.

\section{Neuronal response in normal-weight individuals}

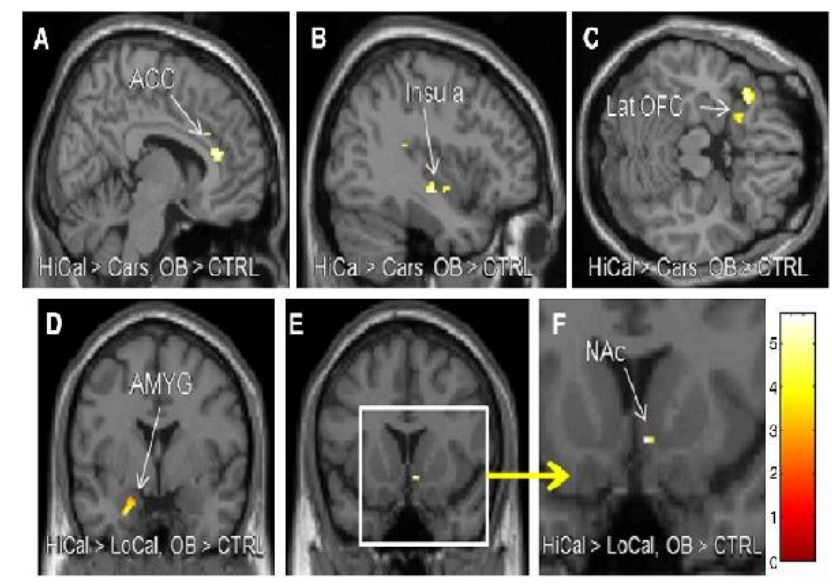

Figure 2.1 Brain regions (Stoeckel et al., 2008)

Traditionally, the hypothalamus is considered the major homeostatic control center. Recent evidence suggests (133) projections of the hypothalamus may influence hedonic-corticolimbic regions that evaluate the emotional, memory, taste and reward 
aspects of food. The corticolimbic brain regions that are consistently activated by visual food cues include the prefrontal cortex (PFC), lateral and medial orbitofrontal cortex (OFC), inferior temporal cortex, parietal cortex, somatosensory cortex, amygdala, hippocampus, parahippocampus gyrus, anterior cingulate, insula, hypothalamus, striatum, pallidum, ventral tegmental area, and the fusiform gyrus $(16,17,29,33,37,38,47-50$, $65,83,90,96,98,101,102,105,118,120-122)$. Collectively these data show brain regions involved in processing attention, emotion, cognition and reward are activated when humans are exposed to visual food cues. While there are considerable differences in regions of activation, they can be attributed to experimental variables such as, stimulus paradigms, gender, hunger level and adiposity. These highly interconnected regions of the corticolimbic brain (86) have been associated with executive functioning, inhibitory and stimulatory behavior, learning and memory, attention, emotion and reward processing in hedonic eating and energy homeostasis $(38,50,90,102)$. The differential neuronal responses of these regions among obese-resistant and obese-prone individuals under fasted or fed conditions can provide insight into control of eating behavior.

In a pioneering fMRI study, Kilgore et al. (50) showed food of different motivational salience (i.e. high-calorie, low-calorie, and non-food related images) resulted in activation of cortical and subcortical brain regions among normal-weight individuals. LaBar et al. (65) showed significant activation in the amygdala, inferior temporal cortex, parahippocampus gyrus, and the anterior fusiform gyrus, in response to food-related visual stimuli in a fasted condition. Analogous findings have been reported in primates (94) and humans $(16,18,33,102)$. However, Kilgore et al. (50) did report similar findings in who had not eaten at least 90 minutes prior to their scan. Taken 
collectively, these findings suggest the amygdala, inferior temporal cortex, parahippocampus gyrus, parietal cortex and fusiform gyrus play critical roles in identifying and processing of visual presented food stimuli. Moreover, it suggests food pictures have greater salience in the fasted state and evoke a stronger BOLD response in normal-weight individuals. In two well controlled studies, Cornier et al. $(16,17)$ reported food pictures presented during a fMRI session to normal-weight men and women that were maintained on a eucaloric diet for 2 days prior, compared to an overfeed diet ( $30 \%$ above EB), showed consistent activation of the insula, inferior temporal cortex, premotor cortex, ventral striatum, OFC, posterior hippocampus and the hypothalamus. This suggests that these regions are associated with visual processing and attention of food images, reward evaluation and regulation of EI. These findings indicate normal-weight individuals are sensitive to the energy surplus associated with overfeeding and thus attenuate their neuronal response to visual food cues. Furthermore, in a review by Cornier (18), it was noted the attenuation of the hypothalamus and insula in response to overfeeding may reflect interactions between visual cues and energy homeostasis in obese-resistant individuals. In fact, the interaction may be a key component which stimulates a return to EB subsequent to a state of energy surplus.

Reduced activation to homeostatic structures coupled with increased activation to PFC regions implicated in the inhibition of inappropriate behavior (e.g. left dorsolateral PFC) $(50,70,71,111)$ could also be a "normal" response to meal induced satiation. In corroboration, feeding studies using PET have reported reductions in $\mathrm{rCBF}$ in homeostatic regions amongst sated, normal-weight subjects $(22,111)$. In line with the presented evidence, Del Parigi et al. (89) postulated that the hypothalamus, thalamus, 
limbic/paralimbic areas, and basal ganglia represent a central orexigenic network. In addition, regions of the PFC have efferent inhibitory projections (61) to this central orexigenic network (especially the lateral hypothalamus) that inhibit effects on eating by suppressing the neuronal activity implicated in the orexigenic network.

Recent evidence suggests an interaction between internal homeostatic processes and reward processes $(63,102)$. Kringelbach et al. (63) showed that feeding subjects to satiety has a negative effect on reported subjective pleasantness of specific taste - a phenomenon referred to as sensory specific satiety. Interestingly, the decrease in pleasantness of food is highly correlated with a reduction in OFC activity (63) an observation that had previously been observed in primates (93). However, recent neuroimaging studies $(33,38,101,102)$ have showed hunger, being the opposite of satiety, increases food reward activity in the OFC of normal-weight adults. In summary, these studies suggest the OFC plays a critical role in the integration of hunger and the incentive salience of food and may also be affected by the stimuli being presented.

Kilgore et al. (50) reported presentation of high-calorie foods compared to lowcalorie foods yielded significantly greater BOLD signal change in bilateral activation within the medial and dorsolateral PFC and thalamus and lateralized activation (i.e. right side) in the cerebellum, medulla, and middle occipital gyrus; regions Kilgore et al. (50) suggests are associated with emotion, motivation, response selection and behavioral regulation. Similar findings have been reported in normal-weight individuals, in addition to the ventral striatum, amygdala, OFC, and the insular cortex $(29,33,38)$. These findings suggest normal-weight individual's attention and motivation to eat is heightened by highly palatable and calorically dense food. Furthermore, significant activation of the 
hypothalamus in response to the highly-palatable visual cues $(50,101)$, suggest an important interaction between external sensory inputs and homeostatic regions of the brain.

In summary, the literature suggests:

- Both cortical and subcortical regions of the brain are activated in response to visual food stimuli.

- Regions of the brain associated with the identification and processing of visual stimuli are activated in response to food cues in normal-weight individuals.

- Food images have greater salience in the fasted state compared to sated or overfeed state in normal-weight individuals.

- Normal-weight individuals promptly and appropriately sense periods of energy surplus associated with overfeeding, resulting in reduce activation of brain regions important in attention, motivation and reward for foods of high salience.

- An interaction between regions implicated in EI and external visual food cues amongst obese-resistant individuals.

- Normal-weight individuals' attention and motivation to eat is heightened by high-calorie foods compared to low-calorie foods. 


\section{Neuronal response in obese individuals}

Recent fMRI studies suggest obese and normal-weight individuals differ substantially in their neural activation in response to visual food cues $(17,83,96,105)$. Cornier et al. (17) demonstrated that overfeed (30\% above EB), overweight individuals did not provoke an attenuation of BOLD signal activation of the right insula, right inferior visual cortex and hypothalamus like in the thin cohort $(16,17)$. Two feeding studies $(21,22)$ did describe similar regions of activation, specifically the insular cortex of sated obese individuals compared to sated lean individuals. In conjunction with previous findings, two recent fMRI studies reported greater BOLD signal activation in identical areas of obese women compared to lean women in response to high-calorie against low-calorie food images $(96,105)$. Furthermore, nearly identical to regions reported by Cornier et al. $(17)$, both studies $(96,105)$ reported greater activation in the lateral $\mathrm{OFC}$, insula, hippocampus, anterior cingulate and dorsal striatum in response to high-calorie foods versus low-calorie foods. In contrast, Gautier et al. $(35,36)$ reported no significant changes amongst obese and lean individuals in prefrontal cortices and limbic/paralimbic areas after eating a satiating meal. However, these findings could have potentially been influenced since subjects were not in an energy surplus state. Strengthening Cornier's et al. $(16,17)$ findings, BMI was positively correlated with degree of activation elicited by the high calorie food pictures specifically in the (medial and lateral) OFC. Contrary, Kilgore \& Todd-Yurgelun (47) reported BMI was negatively correlated with BOLD activity in the inferior OFC gyri. Taken collectively, these findings suggest obese subjects exhibit a different activation pattern in regions associated 
with attention, assigning salience value to food stimuli and EI regulation compared to normal-weight individuals.

In addition, differences have been reported in brain regions associated with emotional, memory, and reward aspects of food in obese and normal-weight individuals $(99,108)$. Stoeckel et al. (104) recently postulated the mechanism for heightened motivational salience of obese individuals may be a hyperactive reward system that includes the nucleus accumbens/ventral striatum, amygdala and the OFC. Stimuli associated with high-calorie foods may trigger excessive motivation for hedonic eating within this reward network that is modulated via the mesocorticolimbic dopamine system (6). Stoeckel et al. (105) showed obese women compared to normal-weight women produced significantly greater activation in the medial and lateral OFC, amygdala, nucleus accumbens/ventral striatum, medial PFC, insula, anterior cingulate cortex, ventral pallidum, caudate, putamen, and hippocampus in response to high-calorie food pictures. Subsequent path analyses (104) revealed an effective connection model amongst the amygdala, OFC and the nucleus accumbens/ventral striatum. Other fMRI studies (96) and PET studies $(21,36)$ have shown greater activation in similar regions of obese women compared to normal-weight women. Collectively, these findings suggest the motivational salience of high-calorie food may be amplified by a hyperactive reward system in obese populations.

Regions of the PFC (i.e. bilaterally the superior prefrontal region and middle frontal gyri and the left dorsolateral PFC) have been implicated in inhibitory control of food intake (20,70, 71, 83). Recently, McCaffery et al. (83) demonstrated successful weight loss maintainers exhibited greater BOLD activity in the left superior frontal region 
and middle frontal gyri in response to food cues relative to normal-weight and obese women. Comparable findings were reported by Del Parigi et al. (20) in successful dieters compared to non-dieters. In line with these findings, Le et al. reported obese men (70) and women (71) compared to lean and formerly obese participants elicited a significant decrease in $\mathrm{rCBF}$ to the left dorsolateral PFC following a satiating meal. In contrast, when comparing obese men to lean men Gautier et al. (35) reported obese men had greater increase in $\mathrm{rCBF}$ to the right dorsolateral and ventromedial PFC. Hence, the inhibitory effect of the PFC may be lateralized, at least in the dorsolateral PFC of men. Moreover, no information was reported on the subject's dietary restraint or previous dieting habits, so the findings could be attributed to this group of obese men attempting to suppress the rewarding signals of food (e.g. similar to that of successful dieters). These findings indicate obese subjects exhibit less activation in regions associated with inhibitory control in response to food cues. Of noteworthy, similar inhibitory control has been reported in smokers (46), thus providing further insight to the mechanism that enables cognitive strategies to modulate cravings.

In summary, the available literature suggests:

- Sated and overfed obese and overweight adults exhibit increased activation compared to lean adults in regions associated with attention, reward evaluation, and indigestive behavior.

- In response to hedonic food, obese subjects compared to normal-weight subjects elicit greater neuronal activation in regions implicated in the reward network. 
- Compared to successful dieters and obese-resistant adults, obese subjects show less activation in regions responsible for inhibitory control of EI.

Sex differences in neuronal response

Satiation seems to influence the motivational salience and processing of food images in a different way amongst men and women $(15,29)$. In a recent study, Frank et al. (29) showed women observing high-calorie food pictures elicited significantly less activation in the superior medial frontal lobe, left middle frontal lobe, left anterior cingulum, right olfactory and bilaterally in the fusiform gyrus when sated compared to being hungry. Under the same experimental conditions, men showed no different activation patterns between the hungry and satiated state. In line with these findings, Cornier et al. (15) reported after 3 days of eucaloric feeding, fasted women showed significantly greater neuronal activation in the dorsolateral PFC, parietal cortex and fusiform gyrus compared to fasted men. Taken collectively, these findings suggest fasted women are more sensitive (or reactive) to hedonic food stimuli than men.

Recent works have yield significantly greater activation in prefrontal $(15,29,49)$ and parieto-temporal $(15,29,118)$ regions in women compared to men. In the whole brain analysis for the high-calorie versus low-calorie food contrast, Kilgore et al. (49) demonstrated women exhibit significantly greater activation compared to men in the orbitofrontal cortices and the dorsolateral PFC, in addition to other limbic/paralimbic areas. In corroboration, Frank et al. (29) and Cornier et al. (15) reported greater activation in women in analogous regions after observing highly palatable food images. Collectively, these finding suggest women have greater attention (parieto-temporal 
response) and cognitive processing (prefrontal response) related to food stimuli. Of noteworthy, Wang et al. (122) did report men were more effective than women at deliberately inhibiting activation in the amygdala, right striatum, left OFC, hippocampus and other regions associated with reward and appetite regulation when viewing highly salient food.

In summary, the available literature suggests:

- Fasting women, compared to men, have a more robust neuronal activation in response to high-calorie foods.

- Women, compared to men, have greater activation in regions associated with attention, decision-making, salience attribution and inhibitory control in response to hedonic food.

\section{Neuronal Response to Exercise}

To our knowledge, there are no published studies that have assessed the impact of exercise on brain responses to visual food cues. However, neuroimaging studies have been used to investigate the brain's response to exercise, but for only short periods of time (<30 min). Liu et al. (75) demonstrated a fatiguing handgrip muscle contraction elicited significant neural activity in motor-function cortices such as the primary sensorimotor cortex, supplementary motor area, and associate cortices (i.e. prefrontal cortex and the cingulate gyrus). The findings were reproduced in a similar study (76), in addition to the primary visual cortex (5). In line with the abovementioned, Benwell et al. $(3,4)$ showed reduced activation in the same regions during the period of recovery $(6-12$ 
min) after a fatiguing handgrip exercise. Taken together, these results suggest that although the reduced functional activation during the recovery period after fatiguing exercise is more marked in motor areas, it also extends to non-motor areas such as the visual cortex.

There is growing evidence that exercise-induced reduction in neural activity within specific regions may be involved in modulation of various physiological $(66,129)$ and behavioral responses (46). The insular cortex has been implicated as an important site of cardiovascular regulation (97) that elicits a neuronal response during exercise (128). In a well-controlled study to determine whether there were differences in the magnitude of insular cortex activation across varying intensities of static (e.g. sustained handgrip exercise at $25 \%$ subjects maximal voluntary contraction) and dynamic (e.g. cycling ergometer at 80-90 bpm and 150-160 bpm) exercises, Williamson et al. (126) concluded during both cycling intensities, that $\mathrm{rCBF}$ to the right insular cortex was related to individual blood pressure changes. Of note, percent change from rest in rCBF to the right insular cortex was greatest after the high-intensity cycling $(13.0 \pm 4.5 \%)$. Furthermore, activation in the insula and anterior cingulate cortices may be independent of muscle metaboreflex activation, which modulates the arterial baroreflex response (44), and blood pressure elevation (127). However, after moderate exercise $(60-70 \%$ heart rate reserve), Williamson et al. $(127,129)$ reported an attenuation in $\mathrm{rCBF}$ to a network of cortical structures (which includes the insula and anterior cortices) (19) that modulates the cardiovascular response during post-exercise hypotension. Deactivation was also observed in the thalamus and sensorimotor regions, which is in line with previous findings $(3,4)$. Taken together, the data suggest cortical and subcortical regions are 
involved in the regulation of cardiovascular responses both during and immediately after (at least 30 minutes) exercise.

Evidence from animal research indicates exercise may influence neurological processes that modulate drug use and responses to contextual cues, specifically through dopaminergic pathways (84). Interestingly, exercise-induced alterations in regional brain activation have been identified in humans viewing smoking-related stimuli (46). This is of note, since previous evidence has shown short (30-40 $\mathrm{min}$ ) moderate-intensity (60$85 \%$ heart rate reserve) exercise reduces self-reported cravings in response to cigarette cues and increases the time (up to $50 \mathrm{~min}$ ) between ad libitum smoking $(112,113)$. In a randomized crossover study, Janse Van Rensburg et al. (46) demonstrated a single bout of exercise (for 10 min at an RPE between 11-13) not only reduced self-reported cigarette cravings but shifted regional brain activation from areas associated with reward processing and visuo-spatial attention to regions related to "default mode network" or normal resting state of the brain (i.e. the brains neural pattern during a non-cognitive task) (40). Janse Van Rensburg et al. (46) findings are in line with Dietrich's (23, 24) 'transient hypofrontality' hypothesis that postulates exercise limits PFC-dependent cognition. Taken collectively, these studies suggests exercise may act as a tool to limit (or even deactivate) frontal cortex regions involved in reward processing of cigarette cravings.

In light of the neuroimaging and behavioral evidence, exercise may have a role in modulating brain activity associated with EI. 
In summary, the available literature suggests:

- There are more widespread changes in cerebral hemodynamic responses to fatiguing hand-grip exercise.

- Exercise-induced reduced functional activation may not be limited to primary motor areas.

- Exercise-induced modifications in cortical and subcortical activity may be a significant factor contributing to cardiovascular regulation.

- A single bout of exercise can modulate an individual's response to an external cue by limiting frontal cortex activation. 


\section{Chapter 3}

\section{Methods and Procedures}

\section{Overview}

The purpose of this study was to determine whether a single bout of exercise alters food reward, visual attention, and inhibitory control regions in the brain assessed by fMRI and subjective appetite responses. A counterbalanced, crossover study design, in which subjects serve as their own control, was used. BOLD in response to rewarding food images was measured after 2 conditions: 1) 60 minutes of aerobic exercise; and 2) No-exercise (60 minutes of rest). See Figure 3.1 for study overview.

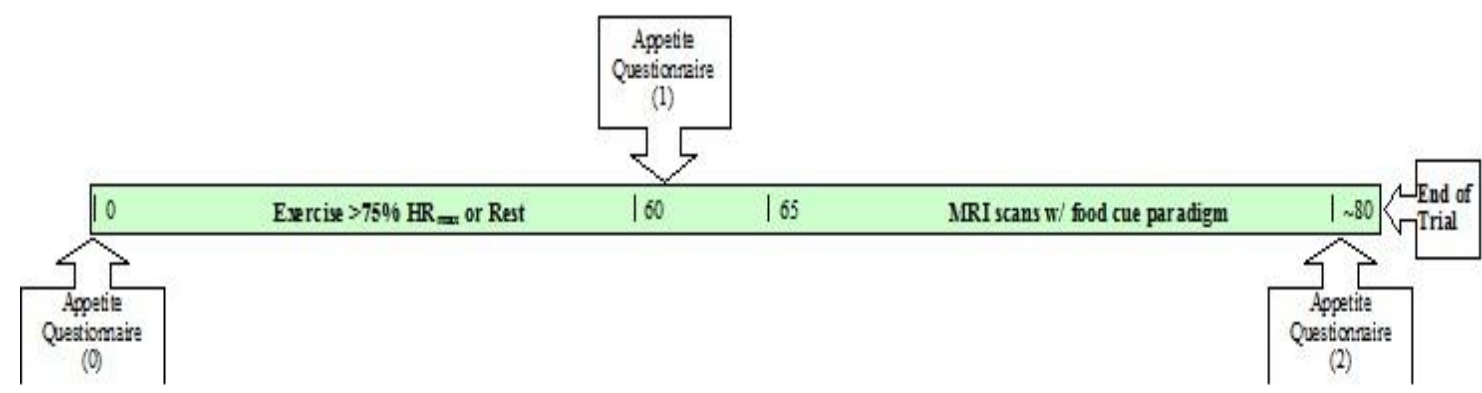

Figure 3.1 Study overview.

\section{Subjects}

Thirty healthy, active ( $>2$ hours of physical activity/week), right handed college students, ages 18-34 were recruited from the local community of San Luis Obispo, CA (see Table 3-1 for subject characteristics). Subjects were recruited through advertisement, fliers and personal announcements. All volunteers were free of any metabolic or chronic disease, non-smoking and physically capable of performing one 
hour of exercise on a stationary cycle ergometer, assessed by Health and Fitness History and Physical Activity Readiness questionnaires (PAR-Q). Exclusion criteria included, standard MRI contraindications (e.g. metal and/or electronic implants, claustrophobia, and pregnancy), neurologic or psychiatric conditions, unsafe dieting practices, a body mass index (BMI) $>30 \mathrm{~kg} / \mathrm{m}^{2}$, body fat $>30 \%$, peak oxygen consumption $\left(\mathrm{VO}_{2 \text { peak }}\right)<35$ $\mathrm{ml} / \mathrm{kg}$-min and any orthopedic or health problem that may have prohibited physical activity. The study was approved by the Human Subjects Committee at California Polytechnic State University, and verbal and written consent were obtained from all subjects.

\begin{tabular}{|cc|}
\hline Variable & Mean $\pm \mathrm{SD}$ \\
\hline \hline $\mathrm{N}(\mathrm{M}, \mathrm{F})$ & 17,13 \\
Age $($ years $)$ & $22.0 \pm 3.8$ \\
$\mathrm{BMI}\left(\mathrm{kg} / \mathrm{m}^{2}\right)$ & $23.6 \pm 2.4$ \\
$\% \mathrm{BF}$ & $16.7 \pm 7.1$ \\
Max Power $(\mathrm{W})$ & $250.9 \pm 65.2$ \\
$\mathrm{VO}_{2 \max }(\mathrm{mL} / \mathrm{kg}-\mathrm{min})$ & $44.3 \pm 8.3$ \\
$\mathrm{HR}_{\max }(\mathrm{bpm})$ & $189.4 \pm 11.3$ \\
\hline Table 3-1. Subject characteristics \\
\hline \hline
\end{tabular}

\section{Preliminary Test}

Subjects completed a Health and Fitness History questionnaire and PAR-Q prior to starting the study. In addition, menstrual cycle phase and any hormonal birth control or estrogen replacement were collected via the Health and Fitness History questionnaire. Total daily energy expenditure (TDEE) for both men and women was predicted from equations developed by Harris and Benedict (41) as described below. This data was used to estimate and determine the percentage of TDEE the exercise bout was. 
Males: TDEE $=[66.47+13.75($ weight in $\mathrm{kg})+5.0($ height in $\mathrm{cm})-6.76($ age in years) $]^{*}($ activity factor)

Females: $\mathrm{TDEE}=[655.1+9.56($ weight in $\mathrm{kg})+1.85($ height in $\mathrm{cm})-4.68$ (age in years) $]^{*}$ (activity factor)

The activity factor $(1.2-1.9)$ was dependent on subject's regular physical activity habits as self-reported. Height was measured by stadiometer (Ellard Instrumentation LTD., Monroe, WA) and weight by balance scale (Continental Scale Corporation, Bridgeview, IL). BMI $\left(\mathrm{kg} / \mathrm{m}^{2}\right)$ was calculated from weight and height and body fat percentage was assessed by bioelectrical impedance (Omron body fat analyzer HBF-301, Vernon Hills, IL) all prior to testing. Demographic information like age and gender was also collected.

Peak oxygen consumption $\left(\mathrm{VO}_{2 \text { peak }}\right)$ was assessed using the Astrand Bicycle Ergometer Maximal Test Protocol (42). The protocol consisted of one 3-minute rest stage followed by 3-minute continuous stages of increasing resistance on the stationary cycle ergometer (Lode Corival 400, Groningen, Nederland); with a constant cadence of $50 \mathrm{rpm}$. The initial power output was $50 \mathrm{~W}$ for women and $100 \mathrm{~W}$ for men. After the initial stage, $30 \mathrm{~W}$ and $50 \mathrm{~W}$ was added to each subsequent stage for women and men respectively. The test continued until 3 of the following 4 conditions were met: 1) Pedal cadence $<50 \mathrm{rpm} ; 2$ ) respiratory exchange ratio $>1.15 ; 3$ ) the subject's heart rate was within 10 beats of age predicted max; and 4) subject voluntarily stopped the test. During the $\mathrm{VO}_{2 \text { peak }}$ test, expired air was collected through a two-way breathing valve that was connected to an online metabolic system (ParvoMedics Truemax 2400, Salt Lake City, 
UT) that was calibrated before each test. $\mathrm{VO}_{2 \text { peak }}$ was determined by the highest 30 second value obtained and maximum wattage was calculated as the proportion of completed stage time over total time of stage achieved ( 3 minutes per stage) multiplied by the expected wattage for that given stage. For example, a female subject completes only $2 \mathrm{~min}(120 \mathrm{~s})$ of the $3 \mathrm{~min}(180 \mathrm{~s})$ stage, the percentage of the stage completed $(120 \mathrm{~s} / 180 \mathrm{~s} \times 100 \%=66 \%)$ will be multiplied by the total wattage of the stage $(30 \mathrm{~W})$ to determine the wattage of her final stage $(.66 * 30 \mathrm{~W}=20 \mathrm{~W})$. Throughout the $\mathrm{VO}_{2 \text { peak }}$ test, heart rate (HR) was continuously monitored using a HR monitor (Polar Electro, Lake Success, $\mathrm{NY}$ ). $\mathrm{VO}_{2 \text { peak }}$, peak watts and $\mathrm{HR}$ was used to determine the appropriate level of physical work during the exercise condition.

\section{Experimental Design}

Subjects were asked to refrain from exercise, alcohol, and caffeine for the previous $24 \mathrm{hrs}$ before all trials. After an overnight fast ( $8-12 \mathrm{hrs})$, all subjects reported to Templeton Imaging Medical Corporation (Templeton, CA) for fMRI scans and all other data collection.

Upon arrival, subjects reviewed a protocol checklist, to check compliance of all pre-trial procedures. Afterward each subject completed an appetite questionnaire to assess subjective appetite responses using a visual analog scale (VAS) (28). Subjects then either rested for 60 minutes or exercised for 60 minutes above $75 \%$ their $\mathrm{HR}_{\max }$ on a cycle ergometer (See Figure 3.1). The order of the exercise or no-exercise condition was organized in a non-randomized counterbalanced order. HR was continuously monitored and recorded throughout the duration of the exercise protocol. During the first ten 
minutes of the exercise protocol, subjects were ramped to a wattage that elicited $>75 \%$ their $\mathrm{HR}_{\max }$, which was determined from subject's $\mathrm{VO}_{2 \text { peak }}$ test. Average HR (bpm), power output (W) was recorded and relative oxygen consumption (ml/kg-min) was calculated from last 30 minutes of steady-state cycling. Relative oxygen costs of cycle ergometry were predicted from a previously validated equation provided by Latin et al. (67) as described below:

VO2 $(\mathrm{mL} / \mathrm{min})=(\mathrm{kgm} / \mathrm{min} * 1.9 \mathrm{~mL} / \mathrm{kgm})+(3.5 \mathrm{~mL} / \mathrm{kg} * \mathrm{~kg}$ of body weight $)+(260$ $\mathrm{mL} / \mathrm{min})$

Total energy expenditure (kcal) was calculated for the entire 60 minute exercise bout. Immediately following the rest or exercise portion of the trial, subjects proceeded to the magnetic resonance (MR) machine after completing another appetite questionnaire. Subjects were then instructed to lie supine on the MR scanner table to be fitted with headphones and head coil by the MRI technician. Visual stimuli were presented from a laptop computer (Dell Latitude E5410) onto a 32" monitor (Vizio, Irvine, CA) outside the scanner room using E-Prime software (Psychology Software Tools Inc., Pittsburgh, PA). Changes in BOLD signals to high- and low-calorie food pictures using fMRI were assessed. Subjects saw images on monitor through a mirror mounted to the head coil. After the scan, subjects were given a final appetite questionnaire and completed a $24 \mathrm{hr}$ dietary recall. There was a one week washout between all trials. 


\section{Visual Food Cue Paradigm}

The food cue paradigm was adapted from Kilgore et al. (55) by using the high quality photographs obtained from the authors. During the fMRI scan subjects completed two stimulation paradigms over two scanning runs in a counterbalanced order: 1) control images and low-calorie foods (see Figure 3.2) and 2) control images and high-calorie foods (see figure 3.3). Control images consisted of non-food objects with similar visual complexity, texture and color (e.g. trees, shrubs and flowers). Low-energy photographs included images depicting fresh fruits and vegetables, whole-grain cereal and garden salads. High-energy photographs included images depicting cheeseburgers, hotdogs, french fries, ice cream sundaes, chocolate chip cookies, barbequed chicken and pasta with meat sauce, etc. Each paradigm lasted for 180s and consisted of three 30 s control blocks which alternated with three 30 s stimulation blocks. Each block consisted of 10 images ( 2 dummy +8 control/stimulation) being presented for $3 \mathrm{~s}$ each. The two dummy images (i.e. images of forks) were used to provide transition from control to stimulation images.

\begin{tabular}{|c|l|l|l|l|l|l|}
\hline Condition & \multicolumn{5}{|c|}{ Time in 30s blocks of 10 images } \\
\hline $\begin{array}{c}\text { Control } \\
\text { images }\end{array}$ & & & & & & \\
\hline $\begin{array}{c}\text { Low-energy } \\
\text { food pictures }\end{array}$ & & & & & & \\
\hline
\end{tabular}

Figure 3.2 Food cue paradigm - Control/Low-energy 


\begin{tabular}{|c|l|l|l|l|l|l|}
\hline Condition & \multicolumn{5}{|c|}{ Time in 30s blocks of 10 images } \\
\hline $\begin{array}{c}\text { Control } \\
\text { images }\end{array}$ & & & & & & \\
\hline $\begin{array}{c}\text { High-energy } \\
\text { food } \\
\text { pictures }\end{array}$ & & & & & & \\
\hline
\end{tabular}

Figure 3.3 Food cue paradigm - Control/High-energy

\section{MRI Data Acquisition}

Functional neuroimaging data was acquired in two runs on a 1.5-T Siemens Symphony MRI scanner (Siemens, New York, NY) equipped with a standard head coil. Functional imaging was collected by using a whole-brain imaging sequence $(\mathrm{TR}=$ $3000 \mathrm{~ms}, \mathrm{TE}=56 \mathrm{~ms}$, field of view $=200 \mathrm{~mm}^{2}, 64^{2}$ acquisition matrix, 30 axial slices, and 3.5-mm slice thickness). BOLD data was collected during 12 blocks in one 12-minute session (see Figure 3.2 and 3.3). For anatomical localization, matched T1-weighted highresolution images was collected of the entire brain $(256 \cdot 256$ matrix, field of view $=256$ $\mathrm{mm}, 1-\mathrm{mm}$ slice thickness) in the sagittal plane as a reference.

\section{fMRI Data Processing and Statistical Analysis}

Functional imaging data was processed and analyzed in SPM8 (Wellcome Trust Centre for Neuroimaging, UK) within the context of the General Linear Model on a voxel by voxel basis (32). Images were corrected for motion using an intrarun realignment algorithm, convolved into the standard Montreal Neurological Institute (MNI) space (using the EPI template found within SPM8) (31) and smoothed using an isotropic Gaussian kernel (full width half-maximum $=7 \mathrm{~mm}$ ) and resliced to $2 \times 2 \times 2 \mathrm{~mm}$. 
As adapted from Stoeckel et al. (105), a two-stage procedure was used for the statistical analysis of a mixed-effects design. At the first level (fixed effects), the fMRI data from each subject was used to generate statistical contrasts maps to compare brain activation to: 1) control vs. high-calorie foods; 2) control vs. low-calorie foods; 3) highcalorie foods vs. low-calorie foods. These contrasts were then entered into a second level (random effects) analysis to compare the exercise and no-exercise conditions along with both sexes. A ROI approach used to address the a priori hypotheses. Given no previous study has examined the brain response of normal-weight or over-weight individuals to visual food cues after a single bout of exercise, a priori ROI that have previously been reported in the regulation of food intake were used (e.g. dorsolateral PFC, OFC, insula and the hypothalamus) $(16,17,50,83)$.

ROI clusters were created using the Wake Forest University PickAtlas (66) and the MarsBaR toolbox (10) in addition to the Anatomic Automatically Labeling toolbox (115) to determine the anatomical location of each locus. As activation within these search territories was predicted to differ between exercise vs. no-exercise and men and women, the ROI analysis was conducted using the MarsBaR toolbox (10). An $\alpha<0.05$ was considered significant. To correct for multiple comparisons in the ROI approach, a Bonferroni correction was applied. Finally, due to the novelty of the study, exploratory voxel-wise group contrasts was performed to identify differences in brain activity outside a priori $\mathrm{ROI}$. The rationale for this analysis was to avoid the possibility of missing any unforeseen condition effects. Therefore, brain activation was evaluated at a threshold of P value of less than 0.005 (uncorrected), with an extent threshold of 5 contiguous voxels, which is standard for exploratory fMRI studies given the relatively novel approach (50). 
An ANOVA was used to determine differences between the exercise and no-exercise conditions.

Minitab 16 Statistical Software (Minitab Inc., State College, PA) was used for statistical analysis of the appetite response. A General Linear Model was used to determine differences in mean hunger, satiety, fullness and prospective food consumption between the exercise and no-exercise conditions. An $\alpha<0.05$ was considered significant.

\section{Sample Size Calculation}

Since no previous study has evaluated the effects of exercise on brain activation in response to visual food cues, results from McCaffrey et al. (83) were used, based on mean changes in the BOLD signal of healthy normal-weight subjects in the superior frontal region. A sample size calculation was conducted using a paired t-test at an $\alpha=$ 0.05 with power of 0.8 , which required a sample size of at least 21 subjects.

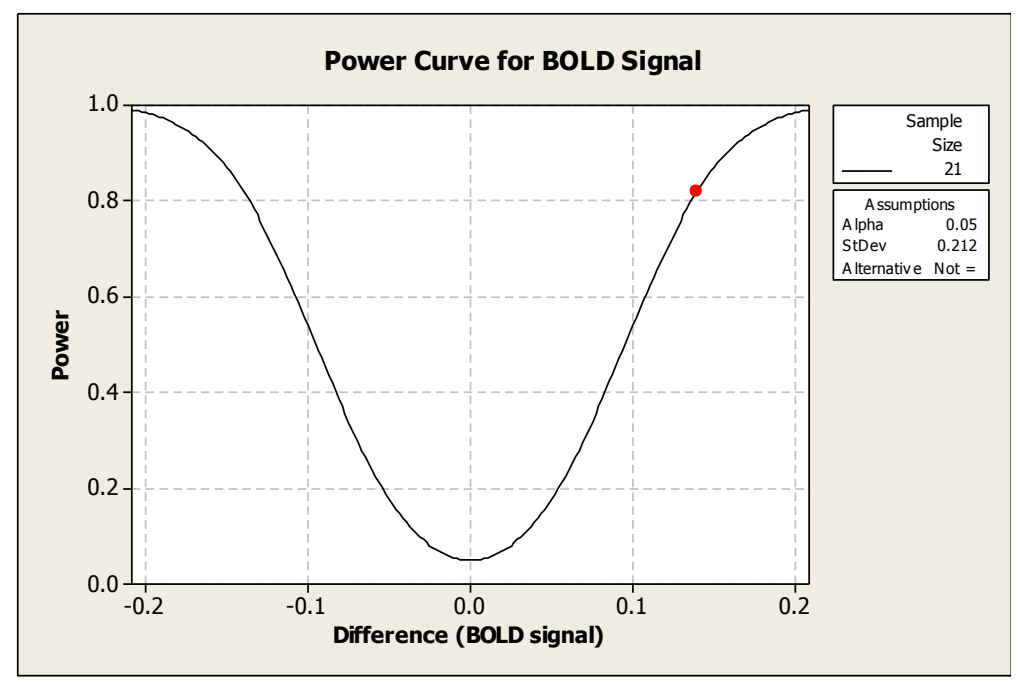

Figure 3.4 Power curve for BOLD Signal 


\section{Chapter 4}

\section{Results}

Assessment of Recruitment and Compliance

Thirty two subjects were originally recruited to the study. Of the 49 people who responded to the initial request for volunteers, 46 were screened and 32 met the inclusion criteria. Two female patients withdrew due to personal reasons. One patient did not adhere to all the study protocol (i.e. consumed one cup of coffee, the morning of the noexercise trial), however his data was still included in the final analysis since it didn't affect the final results. The final analysis included 30 subjects (17 M, $13 \mathrm{~F})$.

\section{Responses to Exercise}

Exercise characteristics are presented in Table 4-1. All subjects completed 60 minutes of high-intensity exercise.

\begin{tabular}{|cc|}
\hline Variable & Mean $\pm \mathrm{SD}$ \\
\hline \hline Duration $(\mathrm{min})$ & 60 \\
$\% \mathrm{HR}_{\max }$ & $82.9 \pm 5.7$ \\
Power $(\mathrm{W})$ & $139.7 \pm 37.7$ \\
$\mathrm{VO}_{2}(\mathrm{~mL} / \mathrm{kg}-\mathrm{min})$ & $29.3 \pm 5.0$ \\
Energy Expenditure (kcal) & $640 \pm 141.5$ \\
\% TDEE & $23.4 \pm 2.8$ \\
\hline Table 4-1. Exercise characteristics
\end{tabular}




\section{ROI Analysis}

The ROI approach to test our a priori hypotheses revealed no structures that were significantly active across both conditions for each condition. A complete list of the ROI analysis can be found in Table 4-2.

\section{Whole Brain Analysis}

Clusters (i.e. contiguous voxels) of significant activation and their mass center coordinates are presented in Table 4-3. Originally, the repeated-measures ANOVA did not show an interaction between the exercise and no-exercise conditions, therefore each condition and food cue was analyzed separately using a one-factor ANOVA. The exploratory analysis revealed significantly active peak clusters $(\mathrm{p}<0.005$, uncorrected) mainly after the exercise condition, compared to the no-exercise condition. For example, post-exercise scans displayed greater activation in prefrontal and visuo-spatial areas such as the superior frontal gyrus (medial surface), medial OFC the precuneus, superior temporal, middle temporal gyrus and the fusiform gyrus. In contrast, the no-exercise condition displayed greater activation in the fusiform gyrus and other subcortical regions.

\section{Sex Differences}

Whole brain analysis revealed a number of significantly active clusters $(p<0.005$, uncorrected) that differed between males and females for the exercise condition. Males showed greater activation in the medial OFC, cuneus and the posterior cerebellum, compared to females who exhibited greater activation in the precuneus and middle temporal gyrus. However, analogous activation was observed in the superior frontal 
gyrus (medial surface) following the exercise condition. In response to the no-exercise condition, males showed greater activation in the lingual gyrus, compared to females who revealed greater activation in the caudate body, fusiform gyrus and the midbrain.

\section{Appetite Scores}

The response plots for hunger, satiety, fullness and prospective food consumption are presented for both conditions in Figure 4.3. A General Linear Model revealed a main effect of condition $(\mathrm{P}=0.023)$, time $(\mathrm{P}<0.001)$, person $(\mathrm{P}=0.002)$ and a condition $\mathrm{x}$ time $(\mathrm{P}=0.002)$ interaction effect for hunger, indicating that responses differed over time between the exercise and no-exercise conditions. Post hoc analysis, using Tukey's Simultaneous test for multiple comparisons indicated hunger decreased significantly immediately after exercise $(\mathrm{P}=0.0006)$ and remained suppressed following the $\mathrm{fMRI}$ scan $(\mathrm{P}<0.0001)$, compared to the no-exercise condition. Furthermore, we observed a main effect for condition $(\mathrm{P}=0.022 ; \mathrm{P}=0.015)$, time $(\mathrm{P}<0.001 ; \mathrm{P}=0.001)$, and person $(\mathrm{P}<0.001 ; \mathrm{P}<0.001)$ for both satiety and fullness, respectively. However, a condition $\mathrm{x}$ time interaction effect, only reached significance for satiety responses $(\mathrm{P}=0.020)$, indicating satiety responses differed over time between the exercise and no-exercise conditions. Post hoc analysis, revealed subjects were more satiated following the fMRI scan after the exercise condition $(\mathrm{P}<0.0001)$, compared to the no-exercise condition. Finally, a main effect of condition $(\mathrm{P}=0.009)$, time $(\mathrm{P}=0.004)$, person $(\mathrm{P}<0.001)$ and a condition $\mathrm{x}$ time $(\mathrm{P}=0.048)$ interaction effect for prospective food consumption, signifying that responses differed over time between the exercise and no-exercise conditions. Tukey's post hoc analysis, revealed subjects were less likely to consume 
food following exercise $(\mathrm{P}=0.0071)$ and the fMRI scan $(\mathrm{P}=0.0002)$, compared to the no-exercise condition.

\begin{tabular}{|c|c|c|c|}
\hline Condition & ROI & $\begin{array}{c}\mathbf{t}- \\
\text { statistic }\end{array}$ & P-value \\
\hline \multicolumn{4}{|l|}{ Exercise } \\
\hline \multicolumn{4}{|l|}{ Hi vs. Con } \\
\hline & DLPFC & 0.47 & 0.788 \\
\hline & Hypothalamus & 0.23 & 0.878 \\
\hline & Insula & -0.98 & 0.999 \\
\hline & $\mathrm{OFC}$ & -0.65 & 0.995 \\
\hline \multicolumn{4}{|l|}{ Low vs. Con } \\
\hline & DLPFC & -1.51 & 1.000 \\
\hline & Hypothalamus & -0.18 & 0.967 \\
\hline & Insula & -2.28 & 1.000 \\
\hline & OFC & -1.91 & 1.000 \\
\hline \multicolumn{4}{|l|}{ Hi vs. Low } \\
\hline & DLPFC & 1.41 & 0.297 \\
\hline & Hypothalamus & 0.20 & 0.889 \\
\hline & Insula & 0.18 & 0.895 \\
\hline & OFC & 1.01 & 0.505 \\
\hline \multicolumn{4}{|l|}{ No Exercise } \\
\hline \multicolumn{4}{|l|}{ Hi vs. Con } \\
\hline & DLPFC & 0.41 & 0.814 \\
\hline & Hypothalamus & -0.87 & 0.999 \\
\hline & Insula & -0.25 & 0.974 \\
\hline & OFC & -0.95 & 0.999 \\
\hline \multicolumn{4}{|l|}{ Low vs. Con } \\
\hline & DLPFC & -0.54 & 0.992 \\
\hline & Hypothalamus & -1.49 & 1.000 \\
\hline & Insula & -1.40 & 1.000 \\
\hline & OFC & -0.60 & 0.994 \\
\hline \multicolumn{4}{|l|}{ Hi vs. Low } \\
\hline & DLPFC & -0.86 & 0.998 \\
\hline & Hypothalamus & -0.57 & 0.993 \\
\hline & Insula & 0.96 & 0.530 \\
\hline & OFC & -0.71 & 0.997 \\
\hline \multicolumn{4}{|c|}{$\begin{array}{l}\text { Table 4-2. ROI analsysis in response visual food cues } \\
\text { after exercise and no exercise conditions. Note: P-values } \\
\text { have been corrected for the multiple regions in the } \\
\text { analysis using the Bonferroni method }\end{array}$} \\
\hline
\end{tabular}




\begin{tabular}{|c|c|c|c|c|}
\hline Condition & Region & MNI Coordinate & $\begin{array}{c}\mathrm{t}- \\
\text { statistic }\end{array}$ & $\begin{array}{c}\text { Cluster } \\
\text { Size }\end{array}$ \\
\hline \multicolumn{5}{|l|}{ Exercise } \\
\hline \multicolumn{5}{|l|}{ Hi vs. Con } \\
\hline & Medial OFC & $1247 \quad-2$ & 3.98 & 476 \\
\hline & Precuneus* & $\begin{array}{lll}6 & -58 & 37\end{array}$ & 6.37 & 1938 \\
\hline \multicolumn{5}{|l|}{ Low vs. Con } \\
\hline & Fusiform gyrus & $45-58 \quad 22$ & 4.02 & 371 \\
\hline & $\begin{array}{c}\text { Superior Temporal } \\
\text { gyrus }\end{array}$ & $45-58 \quad 22$ & 4.29 & 1065 \\
\hline \multicolumn{5}{|l|}{ Hi vs. Low } \\
\hline & $\begin{array}{l}\text { Middle Temporal } \\
\text { gyrus }\end{array}$ & $-48 \quad 2-32$ & 4.45 & 427 \\
\hline & Precuneus* & $\begin{array}{lll}-12 & -52 \quad 28\end{array}$ & 6.05 & 1272 \\
\hline & $\begin{array}{c}\text { Superior Frontal } \\
\text { gyrus }\end{array}$ & $0 \quad 62 \quad 28$ & 4.11 & 919 \\
\hline \multicolumn{5}{|l|}{ No Exercise } \\
\hline \multicolumn{5}{|l|}{ Hi vs. Low } \\
\hline & Fusiform gyrus & $21-79-5$ & 4.59 & 992 \\
\hline & Midbrain & $\begin{array}{lll}12 & -13 & -11\end{array}$ & 4.65 & 363 \\
\hline \multicolumn{5}{|c|}{$\begin{array}{l}\text { Table 4-3. Foci of significantly active clusters }(P<0.005 \text {, uncorrected) in response to visual } \\
\text { food cues after exercise or no exercise conditions }\end{array}$} \\
\hline
\end{tabular}



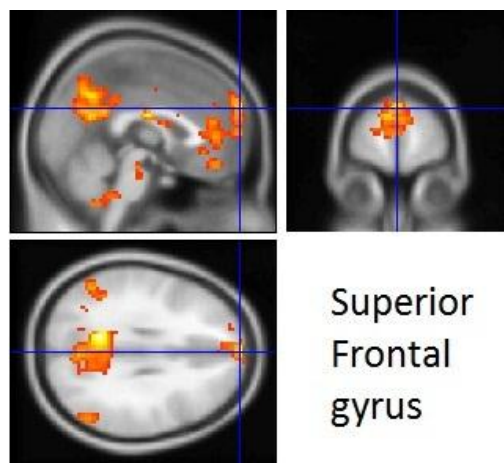

Superior

Frontal

gyrus
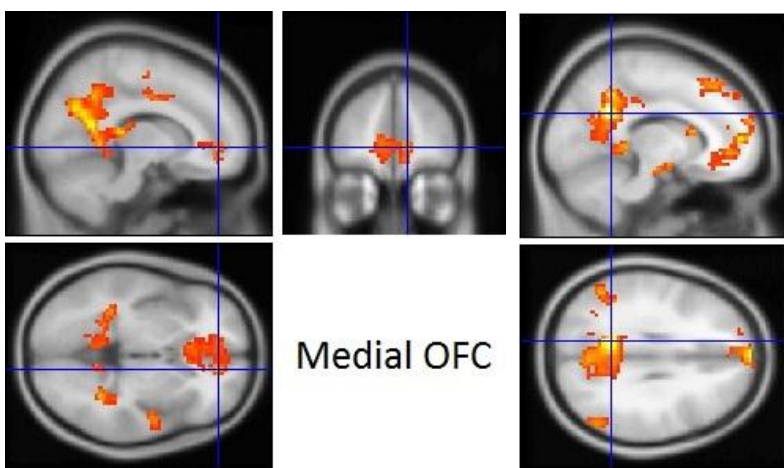

Medial OFC

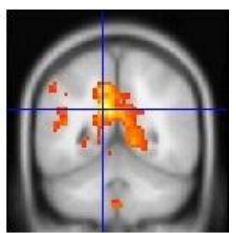

Precuneus

Figure 4.1. Significant clusters. Sagittal, coronal and axial slices of significant clusters $(P<0.005)$ following exercise condition
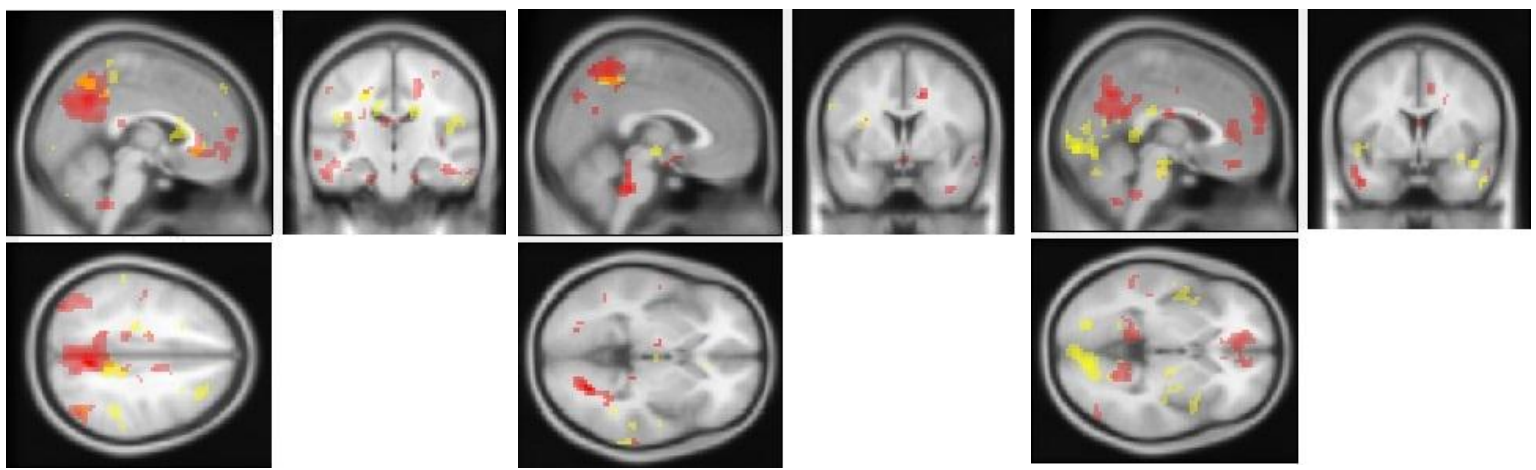

Figure 4.2. Brain Activation of exercise vs. no-exercise. Sagittal, coronal and axial views of areas showing activation in exercise condition (red) relative to no-exercise (yellow) condition 


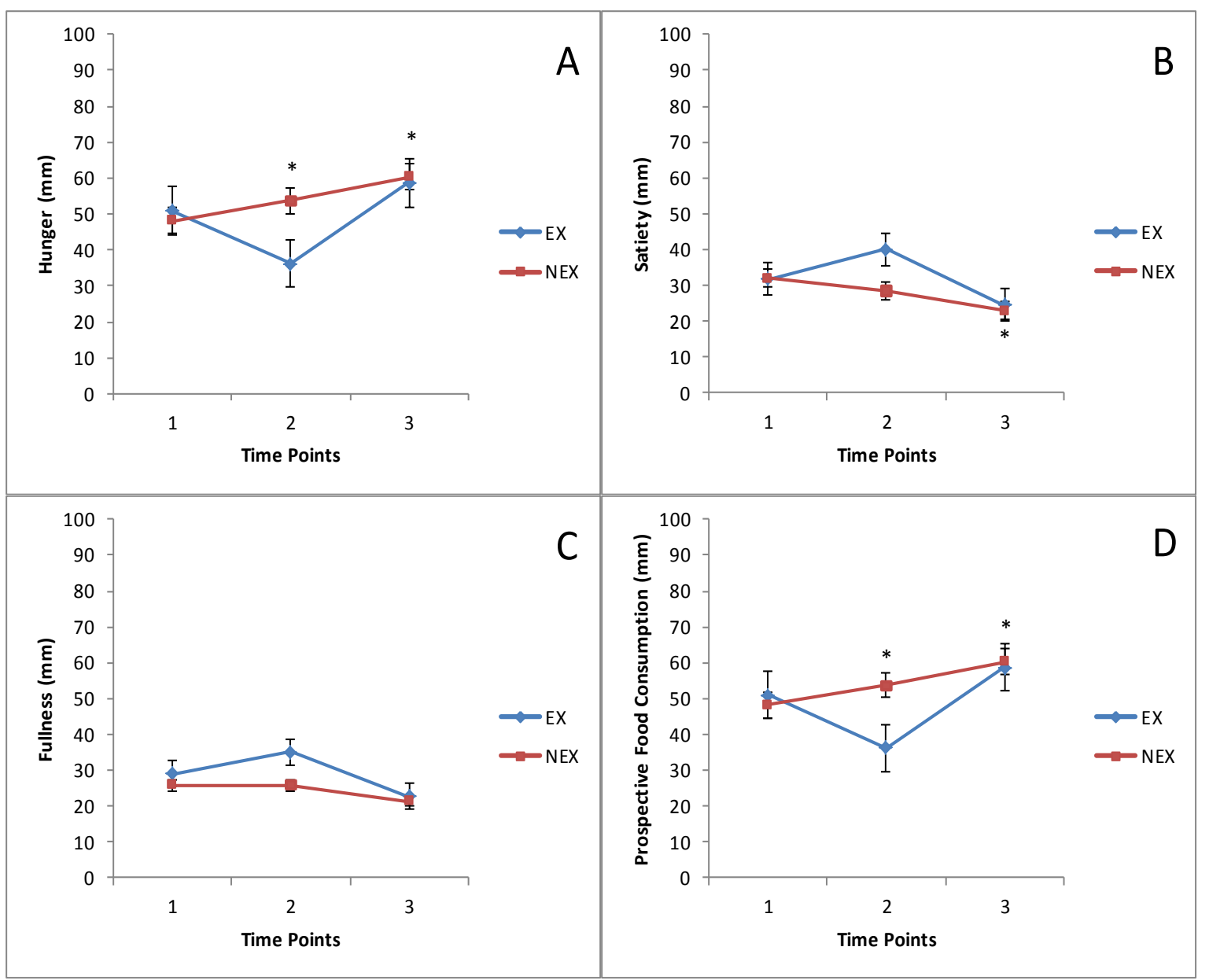

Figure 4.3. Appetite Responses. Mean visual analogue scale scores for changes in hunger (A), satiety (B), fullness ( C) and prospective food consumption between exercise and no exercise conditions. *Values significantly different $(\mathrm{P}<.05)$ than postexercise scores, after Tukey adjustments. Note: time points T1 (baseline), T2 (post-treatment), T3 (post-fMRI scan) 


\section{Chapter 5}

\section{Discussion}

The primary goal of this study was to determine whether a single bout of exercise altered food reward, visual attention, and inhibitory control regions in the brain and subjective appetite responses. The main findings in response to exercise were: 1) Greater activation of an inhibitory region (superior frontal gyrus) and visual attention regions (precuneus, superior temporal gyrus, middle temporal gyrus, fusiform gyrus); 2) however, a food reward region (medial OFC) was activated; and 3) suppression of hunger, satiety and prospective food consumption. The current findings confirm three of our hypothesis, that exercise increases activation in food inhibitory control and visual attention regions, and suppresses subjective appetite responses. However, we did not observe an attenuation of food reward and energy regulating brain regions. Collectively, these data suggest that exercise, at least partially, alters brain responses to food pictures in a direction expected to decrease energy intake.

A novel finding in the current study is a clear effect of exercise on brain activation. We showed that exercise increased brain activation in a food inhibitory region (superior frontal gyrus). These regions within the prefrontal cortex (PFC) have a central role in the inhibition of inappropriate behavior $(61,83)$, satiety $(35)$, and meal termination (70). To our knowledge, only one other study evaluated brain activation in response to exercise using fMRI (46). Janse Van Rensberg et al. (46) found that 10 minutes of exercise increased neural activity in inhibitory regions (e.g. superior frontal gyrus) in response to visual smoking pictures. Others have found that movement or exercise during a fMRI scan increased brain activation in inhibitory control regions (74). 
Our findings are generally consistent with, and extend the results of, those previous studies showing increased inhibitory control brain regions in response to exercise.

We also found that exercise increased activation in the precuneus, superior temporal gyrus and middle temporal gyrus. Activation of these regions is consistent with greater visual processing and visual attention of food cues following an exercise condition, in contrast to no-exercise trial. These finding suggests that a single bout of exercise may lead to a heightened awareness between external signals and energy regulating centers of the brain, especially with the concomitant activation of prefrontal regions. This is in line with previous findings (60) of neural connectivity between associative centers, such as the precuneus and the PFC. These data, combined with our finding that exercise increased activation in inhibitory control brain regions, are consistent with previous studies $(51,54,108)$ showing that energy intake is not increased after exercise.

To our surprise, we did observe activation in a food reward region (medial OFC) following exercise. This finding is in contrast to our hypothesis and the one other exercise study using fMRI (46). Interestingly, Del Parigi et al. (20) suggested that, due to the reciprocally interconnection between the OFC and the DLPFC (i.e. an inhibitory region), there may be an inhibitory feedback circuit that links prefrontal and orbitofrontal regions. The link may be under top-down control, meaning the inhibitory regions may have a regulatory effect on the information processing of the OFC. Furthermore, Plassmann et al. (91) suggested the OFC is an integral function of the goal valuation system or the processing of signals that influence decision-making. Moreover, the system's processing may have hemispheric specialization in the management of reward 
and aversive goals. In an fMRI study, O’Doherty and colleagues (88) found voxels activated in the right OFC were predominately correlated with aversive goal values as opposed to the left OFC which was correlated with reward, following an emotion-related visual reversal-learning task. In the present study, the right OFC was activated following exercise. Hence, it is tempting to speculate the activation of the OFC after exercise was in relation to assigning a goal value that was in opposition of the stimuli being presented, considering it was activated while viewing highly palatable, energy dense food which can lead to severe perturbations in energy balance and undesirable weight gain. Further exploration will need to be conducted to determine the true effect of exercise on OFC activation.

In general, exercise altered subjective appetite responses in a direction expected to suppress energy intake. These results are consistent with previous studies $(11,54,56)$ of prolonged $(\geq 60-\mathrm{min})$ exercise at high-intensities $\left(\geq 70 \% \mathrm{VO}_{2 \max }\right)$ decreasing subjective hunger responses. For example, Broom et al. (12) showed 11 lean, active males, who exercised for 60 minutes at $70 \%$ of $\mathrm{VO}_{2 \max }$ had significantly lower hunger scores during and up to 4 hours after exercise, compared to the no-exercise condition. In the current study, the suppressed appetite responses are in line with greater activation in inhibitory control and visual attention brain regions. Taken together, the increased brain activation and suppressed appetite responses provide a plausible explanation that energy intake is not increased after exercise.

In our study energy intake was not measured, and to date only one other PET study (21) has examined the effects of food intake on brain activation. However, it is still 
unclear how brain activation changes ad libitum food intake since the subjects only consumed a satiating meal that was calculated based off their daily energy requirements.

Several methodological considerations in the current study must be mentioned. First, we only observed significant activation in the fusiform gyrus and the midbrain during the no-exercise condition. These results are in contrast to studies with similar visual food cue paradigms $(50,83)$ and study designs (46). The differences may hinge on numerous variables including subject characteristics (men vs. women), physical activity levels, body composition, magnet strength, etc. In our study, subjects were healthy, normal-weight and habitually active. In contrast, others used sedentary, overweight or obese individuals $(17,71,83)$ or did not report physical activity levels (50). Previous studies have found that habitually active individuals have suppressed appetite hormones and no increase in food intake after exercise $(54,116)$. Therefore, the habitually active individuals in the current study may have improved energy homeostatic controls, potentially explaining the attenuated brain responses observed in the no-exercise trial. Second, the strength of the magnet, a 1.5-T, compared to a stronger 3-T, may have not been robust enough to detect differences in homeostatic and hedonic control feeding centers deep within the brain. Third, due to the novelty of brain mapping using fMRI, we had limited ability to map the connectivity of the significantly activated brain regions, and to determine the influence of the PFC on modulating other cortical and subcortical regions. Finally, our study was under powered to detect sex differences in brain regions, an observation that can have future implications in elucidating sex differences.

Our study has posed some interesting questions, hence there are areas future studies still need to investigate, such as the role cardiorespiratory fitness plays on brain 
activation in response to visual food cues. Moreover, the lack of compensatory increase in energy intake following acute bouts of exercise is short-lived ( $<9$ days $)(108,109)$, thus it would be fascinating to determine how brain responses change as a result of regular exercise training. Furthermore, recent neuroimaging studies (40) have been focusing on the brains' 'default mode', or brain activity during rest. It has been suggested this network may have paramount implications on energy intake and maintaining a healthy body weight (39). Therefore it would be appealing to see how the brains' neural circuitry changes as individuals improve their fitness. Finally, it is critical to reveal the therapeutic efficacy of exercise training on brain activation in obese populations, since they are at greater risk of many weight-related chronic diseases. In summary, our results suggest, at least partially, that exercise alters brain activation in a direction expected to decrease energy intake. Increased activation in food inhibitory centers and visual attention centers is consistent with a non-compensatory increase in energy intake following an acute bout of exercise. From a practical standpoint, these findings imply exercise may alter the physiological drive to eat, by reducing the desire of food, culminating in the absence of increases in energy intake, at least in the short-term. Therefore, increased brain activation may be a plausible mechanism of why there is no compensatory increase in energy intake after exercise. 


\section{References}

1. Applegate EA, Upton DE, Stern JS. Food intake, body composition and blood lipids following treadmill exercise in male and female rats. Physiology \& Behavior 28: 917920, 1982.

2. Ballard TP, Melby CL, Camus H, Cianciulli M, Pitts J, Schmidt S, Hickey MS. Effect of resistance exercise, with or without carbohydrate supplementation, on plasma ghrelin concentrations and postexercise hunger and food intake. Metab. Clin. Exp 58: 1191-1199, 2009.

3. Benwell NM, Byrnes ML, Mastaglia FL, Thickbroom GW. Primary sensorimotor cortex activation with task-performance after fatiguing hand exercise. Experimental Brain Research 167: 160-164, 2005.

4. Benwell NM, Mastaglia FL, Thickbroom GW. Reduced functional activation after fatiguing exercise is not confined to primary motor areas. Experimental Brain Research 175: 575-583, 2006.

5. Benwell NM, Mastaglia FL, Thickbroom GW. Changes in the functional MR signal in motor and non-motor areas during intermittent fatiguing hand exercise. Experimental Brain Research 182: 93-97, 2007.

6. Berridge KC. The debate over dopamine's role in reward: the case for incentive salience. Psychopharmacology 191: 391-431, 2007.

7. Berthoud HR. Mind versus metabolism in the control of food intake and energy balance. Physiology \& behavior 81: 781-793, 2004.

8. Blundell JE, Cotton JR, Delargy H, Green S, Greenough A, King NA, Lawton CL. The fat paradox: fat-induced satiety signals versus high fat overconsumption. Int. J. Obes. Relat. Metab. Disord 19: 832-835, 1995.

9. Blundell JE, Stubbs RJ, Hughes DA, Whybrow S, King NA. Cross talk between physical activity and appetite control: does physical activity stimulate appetite? Proc Nutr Soc 62: 651-661, 2003.

10. Brett M, Anton JL, Valabregue R, Poline JB. Region of interest analysis using an SPM toolbox. Neuroimage 16: 1140-1141, 2002.

11. Broom DR, Stensel DJ, Bishop NC, Burns SF, Miyashita M. Exercise-induced suppression of acylated ghrelin in humans. J Appl Physiol 102: 2165-2171, 2007.

12. Broom DR, Batterham RL, King JA, Stensel DJ. Influence of resistance and aerobic exercise on hunger, circulating levels of acylated ghrelin, and peptide YY in healthy males. Am J Physiol Regul Integr Comp Physiol 296: R29-35, 2009.

13. Catenacci VA, Ogden LG, Stuht J, Phelan S, Wing RR, Hill JO, Wyatt HR. Physical activity patterns in the national weight control registry. Obesity 16: 153-161, 2008. 
14. Cheng MH-Y, Bushnell D, Cannon DT, Kern M. Appetite regulation via exercise prior or subsequent to high-fat meal consumption. Appetite 52: 193-198, 2009.

15. Cornier MA, Salzberg AK, Endly DC, Bessesen DH, Tregellas JR. Sex-based differences in the behavioral and neuronal responses to food. Physiology \& behavior 99: $538-543,2010$.

16. Cornier M-A, Von Kaenel SS, Bessesen DH, Tregellas JR. Effects of overfeeding on the neuronal response to visual food cues. Am J Clin Nutr 86: 965-971, 2007.

17. Cornier M-A, Salzberg AK, Endly DC, Bessesen DH, Rojas DC, Tregellas JR. The Effects of Overfeeding on the Neuronal Response to Visual Food Cues in Thin and Reduced-Obese Individuals. PLoS One 4: 1-7, 2009.

18. Cornier M-A. The effects of overfeeding and propensity to weight gain on the neuronal responses to visual food cues. Physiol. Behav 97: 525-530, 2009.

19. Critchley HD, Corfield DR, Chandler MP, Mathias CJ, Dolan RJ. Cerebral correlates of autonomic cardiovascular arousal: a functional neuroimaging investigation in humans. The Journal of physiology 523: 259-270, 2000.

20. DelParigi A, Chen K, Salbe AD, Hill JO, Wing RR, Reiman EM, Tataranni PA. Successful dieters have increased neural activity in cortical areas involved in the control of behavior. Int J Obes (Lond) 31: 440-448, 2007.

21. DelParigi A, Chen K, Salbe AD, Hill JO, Wing RR, Reiman EM, Tataranni PA. Persistence of abnormal neural responses to a meal in postobese individuals. International Journal of Obesity 28: 370-377, 2004.

22. DelParigi A, Chen K, Salbe AD, Reiman EM, Tataranni PA. Sensory experience of food and obesity: a positron emission tomography study of the brain regions affected by tasting a liquid meal after a prolonged fast. NeuroImage 24: 436-443, 2005.

23. Dietrich A. Transient hypofrontality as a mechanism for the psychological effects of exercise. Psychiatry research 145: 79-83, 2006.

24. Dietrich A, Sparling PB. Endurance exercise selectively impairs prefrontal-dependent cognition. Brain and Cognition 55: 516-524, 2004.

25. Edholm OG, Fletcher JG, Widdowson EM, McCance RA. The energy expenditure and food intake of individual men. British Journal of Nutrition 9: 286-300, 1955.

26. Edholm OG. Energy balance in man. National Institute for Medical Research. J Hum Nutr 31: 413-431, 1977.

27. Flegal KM, Carroll MD, Ogden CL, Curtin LR. Prevalence and Trends in Obesity Among US Adults, 1999-2008. JAMA 303: 235-241, 2010.

28. Flint A, Raben A, Blundell JE, Astrup A. Reproducibility, power and validity of visual analogue scales in assessment of appetite sensations in single test meal studies.

International journal of obesity 24: 38-48, 2000. 
29. Frank S, Laharnar N, Kullmann S, Veit R, Canova C, Hegner YL, Fritsche A, Preissl H. Processing of food pictures: influence of hunger, gender and calorie content. Brain Res 1350: 159-166, 2010.

30. Friston KJ, Ashburner JT, Kiebel SJ, Nichols TE, Penny WD, Corporation E. Statistical parametric mapping: the analysis of functional brain images. Elsevier/Academic Press, 2007.

31. Friston KJ, Ashburner J, Frith CD, Poline JB, Heather JD, Frackowiak RSJ. Spatial registration and normalization of images. Human Brain Mapping 3: 165-189, 1995.

32. Friston KJ, Holmes AP, Worsley KJ, Poline JP, Frith CD, Frackowiak RSJ. Statistical parametric maps in functional imaging: a general linear approach. Human brain mapping 2: 189-210, 1995.

33. Fuhrer D, Zysset S, Stumvoll M. Brain Activity in Hunger and Satiety: An Exploratory Visually Stimulated fMRI Study. Obesity 16: 945-950, 2008.

34. Garrow JS, Summerbell CD. Meta-analysis: effect of exercise, with or without dieting, on the body composition of overweight subjects. European journal of clinical nutrition 49: $1,1995$.

35. Gautier JF, Chen K, Salbe AD, Bandy D, Pratley RE, Heiman M, Ravussin E, Reiman EM, Tataranni PA. Differential brain responses to satiation in obese and lean men. Diabetes 49: 838-846, 2000.

36. Gautier JF, Del Parigi A, Chen K, Salbe AD, Bandy D, Pratley RE, Ravussin E, Reiman EM, Tataranni PA. Effect of satiation on brain activity in obese and lean women. Obes. Res 9: 676-684, 2001.

37. Gizewski ER, Rosenberger C, de Greiff A, Moll A, Senf W, Wanke I, Forsting M, Herpertz S. Influence of Satiety and Subjective Valence Rating on Cerebral Activation Patterns in Response to Visual Stimulation with High-Calorie Stimuli among Restrictive Anorectic and Control Women. Neuropsychobiology 62: 182-192, 2010.

38. Goldstone AP, Prechtl de Hernandez CG, Beaver JD, Muhammed K, Croese C, Bell G, Durighel G, Hughes E, Waldman AD, Frost G, Bell JD. Fasting biases brain reward systems towards high-calorie foods. European Journal of Neuroscience 30: 1625$1635,2009$.

39. González-Hernández JA, Scherbaum WA. Obesity-specific Circuits in the Human Brain: Exploration by Dynamic Brain Self-reference (dynBSR). Hormone and metabolic research 38: 777, 2006.

40. Greicius MD, Krasnow B, Reiss AL, Menon V. Functional connectivity in the resting brain: A network analysis of the default mode hypothesis. Proceedings of the National Academy of Sciences of the United States of America 100: 253 -258, 2003.

41. Harris JA, Benedict FG. A Biometric Study of Human Basal Metabolism. Proc Natl Acad Sci U S A 4: 370-373, 1918. 
42. Heyward VH. Advanced Fitness Assessment and Exercise Prescription. 4th ed. Human Kinetics Publishers, 2002.

43. Hubert P, King NA, Blundell JE. Uncoupling the Effects of Energy Expenditure and Energy Intake: Appetite Response to Short-term Energy Deficit Induced by Meal Omission and Physical Activity. Appetite 31: 9-19, 1998.

44. Ichinose M, Saito M, Wada H, Kitano A, Kondo N, Nishiyasu T. Modulation of arterial baroreflex dynamic response during muscle metaboreflex activation in humans. The Journal of Physiology 544: 939, 2002.

45. Imbeault P, Saint-Pierre S, AlméRas N, Tremblay A. Acute effects of exercise on energy intake and feeding behaviour. British Journal of Nutrition 77: 511-521, 1997.

46. Janse Van Rensburg K, Taylor A, Hodgson T, Benattayallah A. Acute exercise modulates cigarette cravings and brain activation in response to smoking-related images: an fMRI study. Psychopharmacology 203: 589-598, 2009.

47. Killgore WDS, Yurgelun-Todd DA. Body mass predicts orbitofrontal activity during visual presentations of high-calorie foods. Neuroreport 16: 859, 2005.

48. Killgore WDS, Yurgelun-Todd DA. Affect modulates appetite-related brain activity to images of food. International Journal of Eating Disorders 39: 357-363, 2006.

49. Killgore WDS, Yurgelun-Todd DA. Sex differences in cerebral responses to images of high versus low-calorie food. Neuroreport 21: 354-358, 2010.

50. Killgore WDS, Young AD, Femia LA, Bogorodzki P, Rogowska J, Yurgelun-Todd DA. Cortical and limbic activation during viewing of high- versus low-calorie foods. NeuroImage 19: 1381-1394, 2003.

51. King JA, Wasse LK, Ewens J, Crystallis K, Emmanuel J, Batterham RL, Stensel DJ. Differential Acylated Ghrelin, Peptide YY3-36, Appetite, and Food Intake Responses to Equivalent Energy Deficits Created by Exercise and Food Restriction. Journal of Clinical Endocrinology \& Metabolism. .

52. King JA, Miyashita M, Wasse LK, Stensel DJ. Influence of prolonged treadmill running on appetite, energy intake and circulating concentrations of acylated ghrelin. Appetite 54: 492-498, 2010.

53. King JA, Wasse LK, Broom DR, Stensel DJ. Influence of brisk walking on appetite, energy intake, and plasma acylated ghrelin. Med Sci Sports Exerc 42: 485-492, 2010.

54. King JA, Wasse LK, Stensel DJ. The acute effects of swimming on appetite, food intake, and plasma acylated ghrelin. J Obes 2011, 2011.

55. King NA, Blundell JE. High-fat foods overcome the energy expenditure induced by high-intensity cycling or running. Eur J Clin Nutr 49: 114-123, 1995.

56. King NA, Burley VJ, Blundell JE. Exercise-induced suppression of appetite: effects on food intake and implications for energy balance. Eur J Clin Nutr 48: 715-724, 1994. 
57. King NA, Snell L, Smith RD, Blundell JE. Effects of short-term exercise on appetite responses in unrestrained females. Eur J Clin Nutr 50: 663-667, 1996.

58. King NA, Lluch A, Stubbs RJ, Blundell JE. High dose exercise does not increase hunger or energy intake in free living males. European journal of clinical nutrition 51: 478, 1997.

59. Kissileff HR, Pi-Sunyer FX, Segal K, Meltzer S, Foelsch PA. Acute effects of exercise on food intake in obese and nonobese women. American Journal of Clinical Nutrition 52: $240,1990$.

60. Kjaer TW, Nowak M, Kjaer KW, Lou AR, Lou HC. Precuneus-Prefrontal Activity during Awareness of Visual Verbal Stimuli. Consciousness and Cognition 10: 356-365, 2001 .

61. Knight RT, Grabowecky MF, Scabini D. Role of human prefrontal cortex in attention control. Adv Neurol 66: 21-34; discussion 34-36, 1995.

62. Kringelbach ML. Food for thought: hedonic experience beyond homeostasis in the human brain. Neuroscience 126: 807-819, 2004.

63. Kringelbach ML, O'Doherty J, Rolls ET, Andrews C. Activation of the Human Orbitofrontal Cortex to a Liquid Food Stimulus is Correlated with its Subjective Pleasantness. Cerebral Cortex 13: 1064 -1071, 2003.

64. Kringelbach ML, Stein A. Cortical mechanisms of human eating. Forum Nutr 63: 164$175,2010$.

65. LaBar KS, Gitelman DR, Parrish TB, Kim YH, Nobre AC, Mesulam MM. Hunger selectively modulates corticolimbic activation to food stimuli in humans. Behav.

Neurosci 115: 493-500, 2001.

66. Lancaster JL, Woldorff MG, Parsons LM, Liotti M, Freitas CS, Rainey L, Kochunov PV, Nickerson D, Mikiten SA, Fox PT. Automated Talairach atlas labels for functional brain mapping. Human brain mapping 10: 120-131, 2000.

67. Latin RW, Berg KE, Smith P, Tolle R, Woodby-Brown S. Validation of a cycle ergometry equation for predicting steady-rate VO2. Med Sci Sports Exerc 25: 970-974, 1993.

68. Lavin JH, Read NW, Nwajiaku J, Stafford PR, French J. The effect of exercise on subsequent feeding behaviour. In: PROCEEDINGS-NUTRITION SOCIETY OF LONDON. 1998, p. 19-19.

69. Lawton CL, Burley VJ, Wales JK, Blundell JE. Dietary fat and appetite control in obese subjects: weak effects on satiation and satiety. International journal of obesity and related metabolic disorders: journal of the International Association for the Study of Obesity 17: 409, 1993. 
70. Le DSN, Pannacciulli N, Chen K, Del Parigi A, Salbe AD, Reiman EM, Krakoff J. Less activation of the left dorsolateral prefrontal cortex in response to a meal: a feature of obesity. Am J Clin Nutr 84: 725-731, 2006.

71. Le DSN, Pannacciulli N, Chen K, Salbe AD, Hill JO, Wing RR, Reiman EM, Krakoff $\mathbf{J}$. Less activation in the left dorsolateral prefrontal cortex in the reanalysis of the response to a meal in obese than in lean women and its association with successful weight loss. Am J Clin Nutr 86: 573-579, 2007.

72. Lieberman LS. Evolutionary and anthropological perspectives on optimal foraging in obesogenic environments. Appetite 47: 3-9, 2006.

73. Lins TA, Neves PRS, Costa MC, Prado L. Effects of different exercise intensities on energy expenditure and hunger sensation in young adults. Brazilian Journal of Kinanthropometry and Human Performance 12: 359, 2010.

74. Liu JZ, Dai TH, Sahgal V, Brown RW, Yue GH. Nonlinear cortical modulation of muscle fatigue: a functional MRI study. Brain research 957: 320-329, 2002.

75. Liu JZ, Shan ZY, Zhang LD, Sahgal V, Brown RW, Yue GH. Human brain activation during sustained and intermittent submaximal fatigue muscle contractions: an FMRI study. Journal of neurophysiology 90: 300, 2003.

76. Liu JZ, Zhang L, Yao B, Sahgal V, Yue GH. Fatigue induced by intermittent maximal voluntary contractions is associated with significant losses in muscle output but limited reductions in functional MRI-measured brain activation level. Brain research 1040: 44$54,2005$.

77. Lluch A, King NA, Blundell JE. Exercise in dietary restrained women: no effect on energy intake but change in hedonic ratings. Eur J Clin Nutr 52: 300-307, 1998.

78. Lluch A, King NA, Blundell JE. No Energy Compensation at the Meal Following Exercise in dietary Restrained and Unrestrained Women. British Journal of Nutrition 84: 219-225, 2000.

79. Macera CA, Ham SA, Yore MM, Jones DA, Ainsworth BE, Kimsey CD, Kohl HW. Prevalence of physical activity in the United States: behavioral risk factor surveillance system, 2001. Prev Chronic Dis 2: A17, 2005.

80. Maraki M, Tsofliou F, Pitsiladis YP, Malkova D, Mutrie N, Higgins S. Acute effects of a single exercise class on appetite, energy intake and mood. Is there a time of day effect? Appetite 45: 272-278, 2005.

81. Martins C, Morgan LM, Bloom SR, Robertson MD. Effects of exercise on gut peptides, energy intake and appetite. J. Endocrinol 193: 251-258, 2007.

82. Mayer J, Marshall NB, Vitale JJ, Christensen JH, Mashayekhi MB, Stare FJ.

Exercise, food intake and body weight in normal rats and genetically obese adult mice. American journal of Physiology 177: 544, 1954. 
83. McCaffery JM, Haley AP, Sweet LH, Phelan S, Raynor HA, Del Parigi A, Cohen R, Wing RR. Differential functional magnetic resonance imaging response to food pictures in successful weight-loss maintainers relative to normal-weight and obese controls. $\mathrm{Am} \mathrm{J}$ Clin Nutr 90: 928-934, 2009.

84. Meeusen R, Piacentini MF, De Meirleir K. Brain microdialysis in exercise research. Sports Medicine 31: 965-983, 2001.

85. Melby CL, Osterberg KL, Resch A, Davy B, Johnson S, Davy K. Effect of carbohydrate ingestion during exercise on post-exercise substrate oxidation and energy intake. Int J Sport Nutr Exerc Metab 12: 294-309, 2002.

86. Morgane PJ, Galler JR, Mokler DJ. A review of systems and networks of the limbic forebrain/limbic midbrain. Progress in Neurobiology 75: 143-160, 2005.

87. Must A, Spadano J, Coakley EH, Field AE, Colditz G, Dietz WH. The Disease Burden Associated With Overweight and Obesity. JAMA 282: 1523-1529, 1999.

88. O'Doherty J, Kringelbach ML, Rolls ET, Hornak J, Andrews C. Abstract reward and punishment representations in the human orbitofrontal cortex. Nature neuroscience 4: 95-102, 2001.

89. Del Parigi A, Gautier J-F, Chen K, Salbe AD, Ravussin E, Reiman E, Tataranni PA. Neuroimaging and obesity: mapping the brain responses to hunger and satiation in humans using positron emission tomography. Ann. N. Y. Acad. Sci 967: 389-397, 2002.

90. Passamonti L, Rowe JB, Schwarzbauer C, Ewbank MP, von dem Hagen E, Calder AJ. Personality Predicts the Brain's Response to Viewing Appetizing Foods: The Neural Basis of a Risk Factor for Overeating. J. Neurosci. 29: 43-51, 2009.

91. Plassmann H, O'Doherty JP, Rangel A. Appetitive and aversive goal values are encoded in the medial orbitofrontal cortex at the time of decision making. The Journal of Neuroscience 30: 10799, 2010.

92. Pomerleau M, Imbeault P, Parker T, Doucet E. Effects of exercise intensity on food intake and appetite in women. American Journal of Clinical Nutrition 80: 1230, 2004.

93. Rolls ET, Murzi E, Yaxley S, Thorpe SJ, Simpson SJ. Sensory-specific satiety: foodspecific reduction in responsiveness of ventral forebrain neurons after feeding in the monkey. Brain Research 368: 79-86, 1986.

94. Rolls ET. Neural processing related to feeding in primates. Appetite: Neural and behavioural bases Oxford Univ Press: 11-53, 1994.

95. Rolls ET. Sensory Processing in the Brain Related to the Control of Food Intake. Proceedings of the Nutrition Society 66: 96-112, 2007.

96. Rothemund Y, Preuschhof C, Bohner G, Bauknecht H-C, Klingebiel R, Flor H, Klapp BF. Differential activation of the dorsal striatum by high-calorie visual food stimuli in obese individuals. Neuroimage 37: 410-421, 2007. 
97. Ruggiero DA, Mraovitch S, Granata AR, Anwar M, Reis DJ. A role of insular cortex in cardiovascular function. The Journal of Comparative Neurology 257: 189-207, 1987.

98. Santel S, Baving L, Krauel K, Münte TF, Rotte M. Hunger and satiety in anorexia nervosa: fMRI during cognitive processing of food pictures. Brain Res 1114: 138-148, 2006 .

99. Scheurink AJ, Steffens AB, Bouritius H, Dreteler GH, Bruntink R, Remie R, Zaagsma J. Sympathoadrenal influence on glucose, FFA, and insulin levels in exercising rats. Am. J. Physiol 256: R161-168, 1989.

100. Scheurink AJW, Steffens AB. Central and peripheral control of sympathoadrenal activity and energy metabolism in rats. Physiology \& behavior 48: 909-920, 1990.

101. Schur EA, Kleinhans NM, Goldberg J, Buchwald D, Schwartz MW, Maravilla K. Activation in brain energy regulation and reward centers by food cues varies with choice of visual stimulus. International Journal of Obesity 33: 653-661, 2009.

102. Siep N, Roefs A, Roebroeck A, Havermans R, Bonte ML, Jansen A. Hunger is the best spice: an fMRI study of the effects of attention, hunger and calorie content on food reward processing in the amygdala and orbitofrontal cortex. Behav. Brain Res 198: 149$158,2009$.

103. Staten MA. The effect of exercise on food intake in men and women. American Journal of Clinical Nutrition 53: 27, 1991.

104. Stoeckel LE, Kim J, Weller RE, Cox JE, Cook III EW, Horwitz B. Effective connectivity of a reward network in obese women. Brain Research Bulletin 79: 388-395, 2009 .

105. Stoeckel LE, Weller RE, Cook III EW, Twieg DB, Knowlton RC, Cox JE. Widespread reward-system activation in obese women in response to pictures of highcalorie foods. NeuroImage 41: 636-647, 2008.

106. Stricker EM, Verbalis JG. Fluid intake and homeostasis. Fundamental neuroscience American Press: 1091-1099, 1999.

107. Stricker EM. Specific appetites and homeostatic systems. Neural and Metabolic Control of Macronutrient Intake CRC Press: 856-872, 2000.

108. Stubbs RJ, Sepp A, Hughes DA, Johnstone AM, Horgan GW, King N, Blundell J. The effect of graded levels of exercise on energy intake and balance in free-living men, consuming their normal diet. Eur J Clin Nutr 56: 129-140, 2002.

109. Stubbs RJ, Sepp A, Hughes DA, Johnstone AM, King N, Horgan G, Blundell JE. The effect of graded levels of exercise on energy intake and balance in free-living women. International journal of obesity and related metabolic disorders: journal of the International Association for the Study of Obesity 26: 866, 2002.

110. Stubbs RJ, Hughes DA, Johnstone AM, Whybrow S, Horgan GW, King N, Blundell J. Rate and extent of compensatory changes in energy intake and expenditure in response 
to altered exercise and diet composition in humans. American Journal of Physiology Regulatory, Integrative and Comparative Physiology 286: R350 -R358, 2004.

111. Tataranni PA, Gautier JF, Chen K, Uecker A, Bandy D, Salbe AD, Pratley RE, Lawson M, Reiman EM, Ravussin E. Neuroanatomical correlates of hunger and satiation in humans using positron emission tomography. Proc. Natl. Acad. Sci. U.S.A 96: 4569-4574, 1999.

112. Taylor AH, Ussher MH, Faulkner G. The acute effects of exercise on cigarette cravings, withdrawal symptoms, affect and smoking behaviour: a systematic review. Addiction 102: 534-543, 2007.

113. Taylor A, Katomeri M. Walking reduces cue-elicited cigarette cravings and withdrawal symptoms, and delays ad libitum smoking. Nicotine \& tobacco research 9: 1183, 2007.

114. Thompson DA, Wolfe LA, Eikelboom R. Acute effects of exercise intensity on appetite in young men. Medicine \& Science in Sports \& Exercise 20: 222, 1988.

115. Tzourio-Mazoyer N, Landeau B, Papathanassiou D, Crivello F, Etard O, Delcroix N, Mazoyer B, Joliot M. Automated anatomical labeling of activations in SPM using a macroscopic anatomical parcellation of the MNI MRI single-subject brain. Neuroimage 15: 273-289, 2002.

116. Ueda S-ya, Yoshikawa T, Katsura Y, Usui T, Fujimoto S. Comparable effects of moderate intensity exercise on changes in anorectic gut hormone levels and energy intake to high intensity exercise. J. Endocrinol 203: 357-364, 2009.

117. Ueda S-ya, Yoshikawa T, Katsura Y, Usui T, Nakao H, Fujimoto S. Changes in gut hormone levels and negative energy balance during aerobic exercise in obese young males. J. Endocrinol 201: 151-159, 2009.

118. Uher R, Treasure J, Heining M, Brammer MJ, Campbell IC. Cerebral processing of food-related stimuli: effects of fasting and gender. Behav. Brain Res 169: 111-119, 2006.

119. Unick JL, Otto AD, Goodpaster BH, Helsel DL, Pellegrini CA, Jakicic JM. Acute effect of walking on energy intake in overweight/obese women. Appetite. .

120. Verger P, Lanteaume MT, Louis-Sylvestre J. Human intake and choice of foods at intervals after exercise. Appetite 18: 93-99, 1992.

121. Wang G-J, Volkow ND, Telang F, Jayne M, Ma J, Rao M, Zhu W, Wong CT, Pappas NR, Geliebter A, Fowler JS. Exposure to appetitive food stimuli markedly activates the human brain. Neuroimage 21: 1790-1797, 2004.

122. Wang G-J, Volkow ND, Telang F, Jayne M, Ma Y, Pradhan K, Zhu W, Wong CT, Thanos PK, Geliebter A, Biegon A, Fowler JS. Evidence of gender differences in the ability to inhibit brain activation elicited by food stimulation. Proceedings of the National Academy of Sciences 106: 1249 -1254, 2009. 
123. Wang Y, Beydoun MA, Liang L, Caballero B, Kumanyika SK. Will all Americans become overweight or obese? Estimating the progression and cost of the US obesity epidemic. Obesity 16: 2323-2330, 2008.

124. Westerterp K. Alterations in energy balance with exercise. Am J Clin Nutr 68: 970S974, 1998.

125. Westerterp-Plantenga MS, Verwegen CRT, IJedema MJW, Wijckmans NEG, Saris WHM. Acute effects of exercise or sauna on appetite in obese and nonobese men. Physiology and Behavior 62: 1345-1354, 1997.

126. Williamson JW, McColl R, Mathews D, Ginsburg M, Mitchell JH. Activation of the insular cortex is affected by the intensity of exercise. J. Appl. Physiol 87: 1213-1219, 1999.

127. Williamson JW, McColl R, Mathews D. Evidence for central command activation of the human insular cortex during exercise. Journal of Applied Physiology 94: 1726, 2003.

128. Williamson JW, Nobrega ACL, McColl R, Mathews D, Winchester P, Friberg L, Mitchell JH. Activation of the insular cortex during dynamic exercise in humans. The Journal of Physiology 503: 277-283, 1997.

129. Williamson JW, Querry R, McColl R, Mathews D. Are decreases in insular regional cerebral blood flow sustained during postexercise hypotension? Med Sci Sports Exerc 41: 574-580, 2009.

130. Woo R, Garrow J, Pi-Sunyer F. Voluntary food intake during prolonged exercise in obese women. The American Journal of Clinical Nutrition 36: 478 -484, 1982.

131. Woo R, Garrow JS, Pi-Sunyer FX. Effect of exercise on spontaneous calorie intake in obesity. American Journal of Clinical Nutrition 36: 470, 1982.

132. Woods SC. The eating paradox: how we tolerate food. Psychol Rev 98: 488-505, 1991.

133. Zheng H, Corkern M, Stoyanova I, Patterson LM, Tian R, Berthoud HR. Peptides that regulate food intake: appetite-inducing accumbens manipulation activates hypothalamic orexin neurons and inhibits POMC neurons. American Journal of Physiology-Regulatory, Integrative and Comparative Physiology 284: 1436, 2003. 
Appendix A: Informed Consent

California Polytechnic State University

\section{INFORMED CONSENT TO PARTICIPATE IN A RESEARCH PROJECT ON THE EFFECTS OF EXERCISE ON BRAIN RESPONSES TO FOOD PICTURES}

INVESTIGATORS: A research project on brain activity is being conducted by Todd Hagobian, Ph.D. (thagobia@calpoly.edu) and graduate student Nero Evero (oevero@calpoly.edu) in the Kinesiology Department at Cal Poly, San Luis Obispo. The purpose of the study is to determine the effect of exercise on brain regions known to alter appetite. To do that, you will undergo a functional magnetic resonance imaging (fMRI) scan at Templeton Imaging Medical Corporation, Inc., on two separate visits.

PURPOSE: You are being asked to participate in a research study. Your participation is voluntary. If you are a student, your decision whether or not to participate will not have any affect on your academic status. Please feel free to ask questions at any time if there is anything you do not understand. The goal of this study is to determine the effects of exercise on brain regions that alter appetite. A single exercise session has been shown to decrease food intake, but it remains unclear whether brain imaging may differ after exercise. Your participation will include 4 visits (see below) and will take approximately 6 hours total. On two of these visits you will be asked to exercise. Your brain activity will be measured with a fMRI scanner at Templeton Imaging Medical Corporation, Inc. Careful measurements of your responses will be used to relate brain activity to appetite. You are being asked to participate because you are a normal, healthy man or woman and are 18 to 40 years old and right-handed. Up to 30 subjects will participate in this study. Your participation allows us to determine basic principles of brain organization and how exercise may be used as a tool to alter appetite. Please be aware that you are not required to participate in this research and you may discontinue your participation at any time without penalty or loss of benefits.

\section{OVERVIEW OF STUDY:}

Visit 1: Informed consent, and measurement of physical characteristics, and health history, appetite and physical activity questionnaire (approximately 1 hour)

Visit 2: Maximal oxygen consumption exercise test (approximately 1 hour)

Visit 3 and 4: Exercise, MRI scan, appetite questionnaire (approximately 4 hours total) 


\section{STUDY PROCEDURES:}

Visit 1: You will be provided with a full description of the study and have the opportunity to ask any questions. At this time you should inform the investigators of any other studies that you are participating in. If you are interested in participating in the study, you will be familiarized with the exercise procedures and equipment, and your body height, body weight, and body fat will be measured. Body fat will be measured by bioelectrical impedance. You will wear no metal objects, and lay down comfortably on a table. You will hold the bioelectrical impedance with your two hands, and your body fat will be measured. Also, you will be asked to complete a questionnaire about your health, appetite, and your physical activity levels. This testing will happen in the Human Performance laboratory at Cal Poly San Luis Obispo.

Visit 2: Maximal oxygen consumption will be determined by exercising on a stationary bicycle. You will be wearing a heart rate monitor and breathe into a mouthpiece and tube. A clip will be placed on your nose so that you can only breathe through your mouth. You will begin pedaling at a very easy workload as a warm-up. You will continue to pedal at the same rate while the workload is increased slightly every 2 minutes. It will become more and more difficult to maintain your pedaling rate as the test progresses. The test will be stopped when you no longer wish to continue (test usually lasts a total of $8-15$ minutes). This test is physically demanding and you may feel fatigued after the test. The results of this standard test will be used to set the appropriate level of physical work during the exercise test.

Visit 3 and 4: Visit 3 and 4 both will occur at Templeton Imaging Medical Corporation in the morning after 8-10 hours of having not eaten food. On both visits you will undergo an fMRI scan. On one of these visits you will exercise for 1 hour prior to the scan and on the other visit you will sit quietly in a chair for 1 hour prior to the scan.

fMRI: This is a special three-dimensional picture of the brain using magnetic waves. You will lie inside a narrow tube for up to one hour. Throughout the study you will be visible to the experimenter by means of a window and you will be in direct verbal communication with fMRI personnel at all times. You will view pictures of different types of food on a computer screen specially designed to work with the fMRI machine. During the scan it is very important to remain as still a possible since the brain imaging is very sensitive to movement. You will not have to hold still for the entire hour, only up to 10 minutes at a time during the actual data collection. You will be given breaks so you can move your head and body while you are in the MRI. You will be given specific instructions as to when the scan will start and stop through a headset that you will wear. There is a panic button that will allow the technician or researchers to stop the scan and for you to immediately exit the fMRI machine. Please ask the experimenter any questions that may arise.

Please Note: $\mathrm{fMRI}$ is commonly used in medicine for the purpose of diagnosing abnormalities of the brain. The procedures that are to be used in this study are different from fMRI scanning used in medicine. There is no intention to make any medical diagnosis with the fMRI as used in this 
research setting. Although unlikely, it is not uncommon that a brain abnormality will be suspected. If this is the case, your scan will be forwarded to your doctor and you will be excluded from participating in the rest of the study.

Each scanning session will last approximately 60 minutes. Several types of brain image data may be collected as part of this investigation. Some of the scans may involve investigational sequences provided by the scanner manufacturer for research purposes. The scans will include one or more of the following:

- A scout image for use in aligning the scanner's field of view

- A quick anatomical image of your brain structure for use in data processing

- Series of brain images collected over time that track brain function in response to visual pictures

- A high-quality image of your brain structure for use in the display of results

Also, at the end of the study you will be given a DVD with your brain photos.

Exercise: Before one of the fMRI scans, you will pedal on a stationary bicycle at a somewhat hard pace for approximately 1 hour. You will be wearing a heart rate monitor during exercise. The pedaling resistance or treadmill grade will be adjusted during the first 15 minutes of exercise until the rate at which you are working is steady at the desired value. The exercise should feel slightly difficult but not painful; you will probably feel fatigued near the end but will not be giving an all-out effort.

Appetite Questionnaire: On visit 3 and 4, immediately before and after the MRI scan, you will answer a few questions regarding your appetite.

ALTERNATIVES: There are no alternative techniques that can provide this type of information on human structure and function. If you are a student subject, there are alternative experiments available for you to participate in.

\section{RISKS:}

fMRI scans: The risks of participation in the MRI scanning procedure are minimal. There is no measurable risk to being exposed to magnetic fields at the strength used in this experiment. There is no long-term safety data available for exposure to multiple MRI scans. Special considerations are made for the following:

1. Metal: The fMRI machine produces a constant, strong magnetic field, so if you have metal implants and clips within your body they may be influenced by the magnetic field and shift in 
position. Thus, if you have such implants you must inform us and withdraw from the study. Metal earrings and necklaces also must be removed prior to the study. If you have shrapnel, surgical implants, or other pieces of metal in your body that cannot be removed, you may not be able to participate in studies involving the fMRI scanner. In many cases, people having dental appliances in their mouths can participate but should notify the investigator to be certain. Clothing with metal cannot be worn in the scanner. We can provide suitable clothes for the study as needed.

2. Women of child bearing potential: The risks of an fMRI scan to the unborn fetus are unknown. By signing this informed consent form you are indicating to the best of your knowledge that you are not pregnant or trying to become pregnant. If you are uncertain then you will be excluded from the study.

3. Hearing: Functional fMRI scanning produces a loud high-frequency tone. To minimize this sound, adequate hearing protection in the form of headset and foam earplugs will be provided and required. The technician and/or researchers will be able to communicate to you through the headset. If you have any hearing issues, you will be excluded from the study.

4. Claustrophobia: The functional scanning coil fits closely around your head, so if you feel anxious in confined spaces, you may not want to participate. If you decide to participate, and then at a later time decide to discontinue, just let us know and we will stop the experiment.

BENEFITS: There are no direct benefits to you in participating in an fMRI study of brain function. These data are collected purely for the purposes of research and do not have a clinical or diagnostic value. However, these data may further our understanding of how exercise may be used as a tool to alter brain activity and help identify the processes that may underlie obesity and regulation of appetite.

CONFIDENTIALITY: We are required by law to protect your confidentiality. All records and assessment data from this study will be treated as confidential. Your name and the fact that you are in the study will be kept confidential. Information stored on our computer will be password protected. Information on fMRI scans and questionnaires will be identified by participant ID and decoded using a list kept in a locked cabinet. Only research staff and the principal investigator will have access to the locked cabinet. All questionnaires and data collection material completed in this study will be shredded within five years after the study's completion.

COSTS/PAYMENTS: There are no costs to you for your participation in this study. You will be paid a maximum of $\$ 40$ for your participation using the following guidelines: 
Completion of Visits 1 and $2=\$ 5$

Completion of all 4 Visits $=\$ 40$

YOUR RIGHT TO WITHDRAW FROM THE STUDY: You may refuse to participate at any time. You may change your mind about being in the study and quit after the study has started. If you are a student your decision whether or not to participate will not have any effect on your academic status. You may withdraw from the study at any time and for any reason. Your decision whether or not to participate in this study, or a decision to withdraw will not involve any penalty or loss of benefits to which you are entitled.

QUESTIONS: If you have questions regarding this study or would like to be informed of the results when the study is completed, please feel free to contact Dr. Todd Hagobian (thagobia@calpoly.edu; 805-756-7511) or Nero Evero (909-996-5130; oevero@calpoly.edu). If you have questions or concerns regarding the manner in which the study is conducted, you may contact Dr. Steve Davis, Chair of the Cal Poly Human Subjects Committee, at (805) 756-2754, sdavis@calpoly.edu, or Dr. Susan Opava, Dean of Research and Graduate Programs, at (805) 756-1508, sopava@calpoly.edu.

If you agree to voluntarily participate in this research project as described, please indicate your agreement by signing below. Please keep one copy of this form for your reference, and thank you for your participation in this research.

Signature of Volunteer

Date 
Appendix B: Health \& Fitness History Questionnaire

Health \& Fitness History

Subject \#:

Date:

Age:

Height $(\mathrm{cm})$ :

Weight (kg):

BMI $\left(\mathrm{kg} / \mathrm{m}^{2}\right)$ :

1. Have you ever been diagnosed as having any of the following and if yes, how are you currently treating the condition?

Y N High Blood Pressure

Y N High Cholesterol or High Triglycerides

Y N Diabetes

Y N Hypoglycemia (low blood sugar)

Y N Asthma

2. Does anyone in your family (immediate family including your grandparents) have a history of cardiovascular disease? (heart attacks, strokes, etc.) Please explain:

3. Does anyone in your family (immediate family including your grandparents) have a history of type 2 diabetes? Please explain:

4. Have you ever had a glucose tolerance test? $\mathrm{Y} N$

If yes, what were the results? 
5. Have you ever had a fasting blood sugar test? $\mathrm{Y} N$

If yes, what were the results?

6. For women:

- Are you pregnant or plan on becoming pregnant within the next year? $\quad \mathrm{Y} \quad \mathrm{N}$

- Are you on hormonal birth control (pill, patch, etc) or estrogen replacement? Describe in detail (e.g. the type):

- What was the date of your last menstruation? Is your cycle regular?

- Do you know the phase of your current menstrual cycle? $\mathrm{Y} N$ If yes, please explain:

7. Do you have any neurological problems including fainting, dizziness, headaches or seizures; or diagnosed psychological disorders?

8. Do you have any orthopedic or other health problems that may affect your ability to perform exercise? If yes, please explain.

9. Are you currently taking any medications, including over-the-counter drugs such as aspirin, Tylenol or Ibuprofen? Please list: 
10. Do you smoke or use smokeless tobacco? $\mathrm{Y} N$

11. Do you drink coffee or other caffeinated beverages? $\mathrm{Y} N$ What kind, how much and how often?

12. Please list all vitamins, minerals and herbs and other nutritional supplements you're taking:

13. Do you have any food allergies or intolerances? $\quad \mathrm{N}$ Please describe:

14. How would you describe the type of diet you currently eat? Have you recently been on any special diets? What kinds of diets have you used to lose weight or lower cholesterol? Please list and describe:

15. What changes have you made in your diet in the last 6 months? Have you gained or lost more than 10lbs within the last year?

16. Do you exercise regularly? $\mathrm{Y} \quad \mathrm{N} \quad$ What kinds of exercise?

How often? 
Please describe how much walking you do on a daily basis:

17. How does your current exercise and physical activity compare to 6 months ago? 1 year ago?

18. How much did you weigh at birth (if known)?

19. Have you had a physical exam in the past two years? $\mathrm{Y} N$ Please describe your assessment of your overall health:

20. Do you have any shrapnel, metal objects (plates, rods, screws, etc.), or electronic devices implanted in your body, or wear braces? $\mathrm{Y} N$ If yes, please describe:

21. Do you wear corrective eyeglasses? $\mathrm{Y} N$

22. Do you, or have you had any hearing issues? $\mathrm{Y} N$ If yes, please describe: 
23. Are you claustrophobic or have any issues being in small spaces? $\mathrm{Y}$ If yes, please describe:

24. Are you: left-hand dominate right-hand dominate mixed dominate (Please check one)

\section{Participant's Signature:}

$$
\text { Date: }
$$


Appendix C: Appetite Questionnaire

Appetite Questionnaire

Subject \#:

Date:

0

Instructions: $\quad$ Please quantify your feel for the aspects mentioned below.

Consider the line as the extremes of your feeling.

Draw a vertical line at the level that best represents your feeling at that moment.

How hungry do you feel?

\begin{tabular}{|l|l|c|c|c} 
I am not \\
hungry at all
\end{tabular}

How satisfied do you feel?

\begin{tabular}{c|c|l}
$\begin{array}{c}\text { I am } \\
\text { completely } \\
\text { empty }\end{array}$ & I cannot eat \\
& another bite
\end{tabular}

How full do you feel?

Not at all full

Totally full 


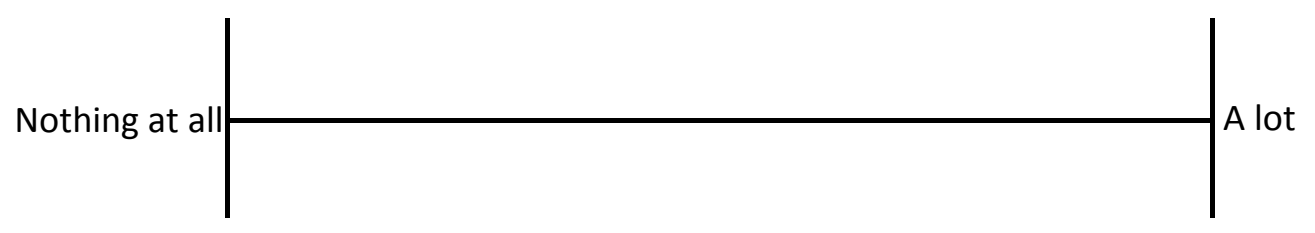

Would you like to eat something sweet?

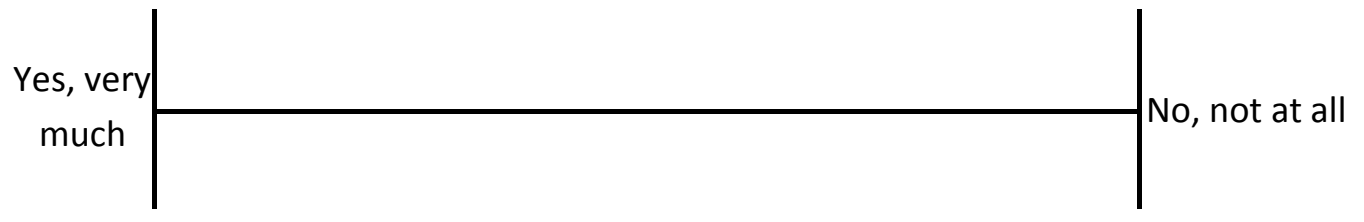

Would you like to eat something salty?

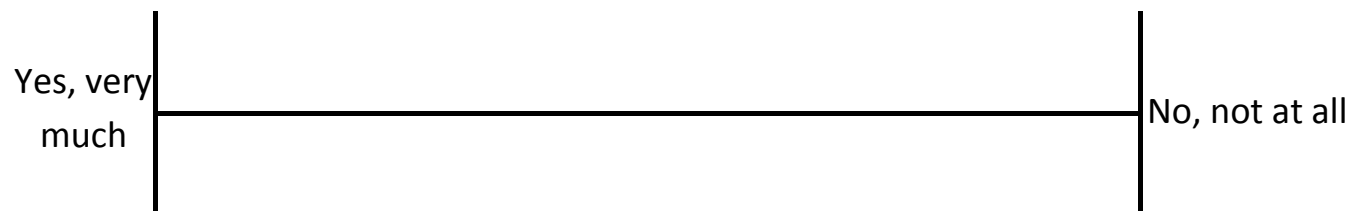

Would you like to eat something savoury?

\begin{tabular}{c|c|c} 
Yes, very & No, not at all \\
\cline { 2 - 3 } & &
\end{tabular}


Would you like to eat something fatty?

\begin{tabular}{c|c|c} 
Yes, very & No, not at all \\
\cline { 2 - 3 } & Nuch &
\end{tabular}

